WSRC-TR-2002-00364, REV. 0

SRT-RPP-2002-00194. REV. 0

\title{
REAL-TIME CHORD LENGTH ANALYSIS OF STRONTIUM AND MANGANESE PRECIPITATES FORMED FROM HANFORD TANK 241-AN-107 SIMULANT (U)
}

DECEMBER 2002

Waste Processing Technology

Savannah River Technology Center

Westinghouse Savannah River Company

Savannah River Site

Aiken, SC 29808

Prepared for the U.S. Department of Energy Under Contract Number DEAC09-96SR18500

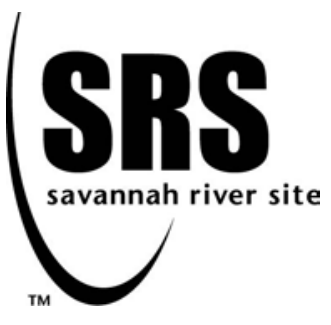


This document was prepared in conjunction with work accomplished under Contract No. DE-AC09-96SR18500 with the U. S. Department of Energy.

\section{DISCLAIMER}

This report was prepared as an account of work sponsored by an agency of the United States Government. Neither the United States Government nor any agency thereof, nor any of their employees, makes any warranty, express or implied, or assumes any legal liability or responsibility for the accuracy, completeness, or usefulness of any information, apparatus, product or process disclosed, or represents that its use would not infringe privately owned rights. Reference herein to any specific commercial product, process or service by trade name, trademark, manufacturer, or otherwise does not necessarily constitute or imply its endorsement, recommendation, or favoring by the United States Government or any agency thereof. The views and opinions of authors expressed herein do not necessarily state or reflect those of the United States Government or any agency thereof.

This report has been reproduced directly from the best available copy.

Available for sale to the public, in paper, from: U.S. Department of Commerce, National Technical Information Service, 5285 Port Royal Road, Springfield, VA 22161, phone: (800) 553-6847, fax: (703) 605-6900

email: orders@ntis.fedworld.gov

online ordering: http://www.ntis.gov/help/index.asp

Available electronically at http://www.osti.gov/bridge

Available for a processing fee to U.S. Department of Energy and its contractors, in paper, from: U.S. Department of Energy, Office of Scientific and Technical Information, P.O. Box 62, Oak Ridge, TN 37831-0062,

phone: (865)576-8401,

fax: (865)576-5728

email: $\underline{\text { reports@ adonis.osti.gov }}$ 
WSRC-TR-2002-00364, REV. 0-A

SRT-RPP-2002-00194. REV. 0-A

Key Words:

Lasentec

FBRM

Particle Size

Retention:

Permanent

Key WTP R\&T References:

Test Specification - TSP-W375-01-00001, Rev. 0

Test Plan - WSRC-TR-2001-00261, Rev. 0

\section{REAL-TIME CHORD LENGTH ANALYSIS OF STRONTIUM AND MANGANESE PRECIPITATES FORMED FROM HANFORD TANK 241-AN-107 SIMULANT (U)}

William D. King, 773-42A

Scott W. Rosencrance, 735-11A

Myra P. Bussey, 735-11A

ISSUE DATE: December 2002

Westinghouse Savannah River Company

Savannah River Site

Aiken, SC 29808

Prepared for the U.S. Department of Energy Under Contract Number DE-AC09-96SR18500

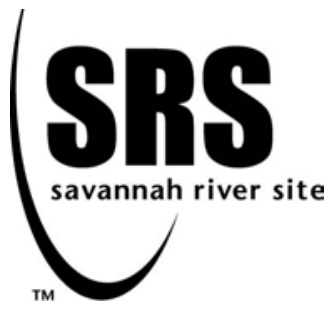


WSRC-TR-2002-00364, REV. 0

SRT-RPP-2002-00194. REV. 0

\section{TABLE OF CONTENTS}

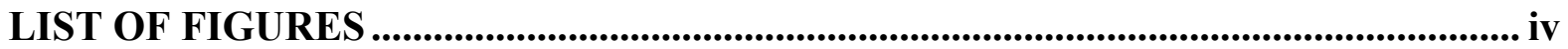

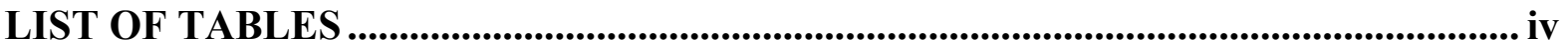

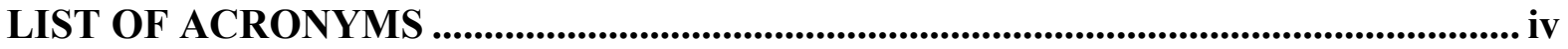

1.0 Executive Summary ............................................................................................................... 1

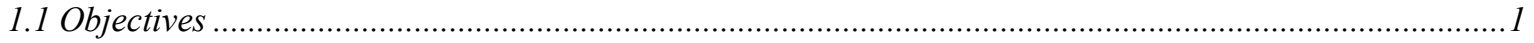

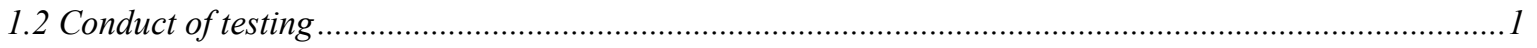

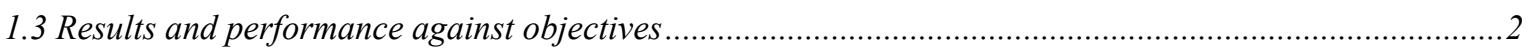

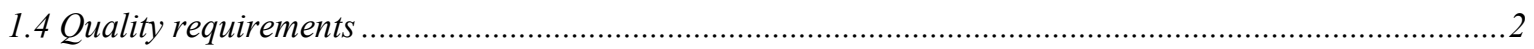

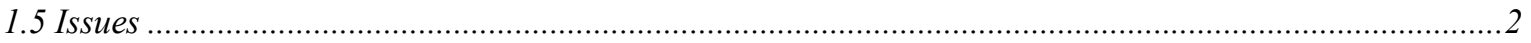

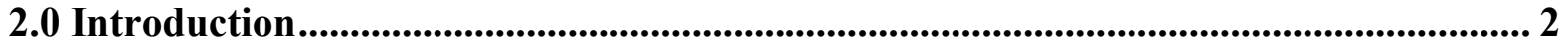

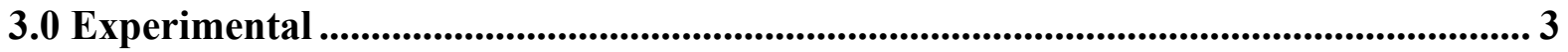

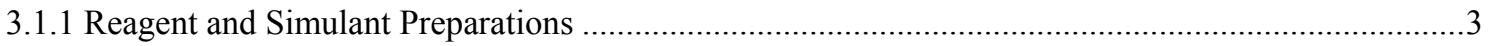

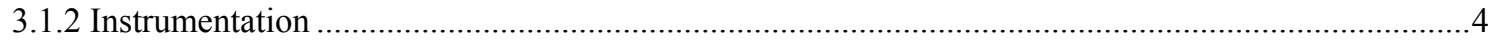

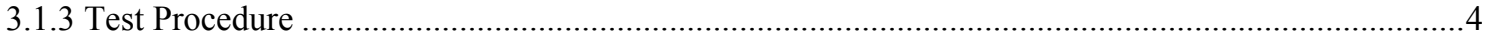

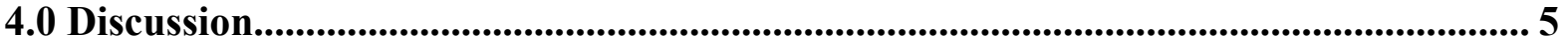

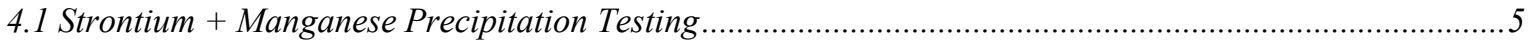

4.2 Precipitation from Caustic Simulant Adjustment .............................................................................. 7

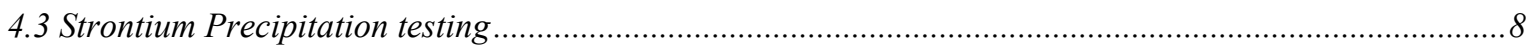

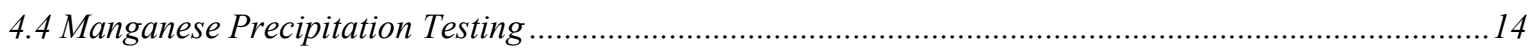

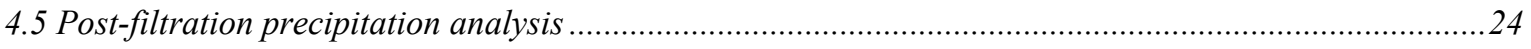

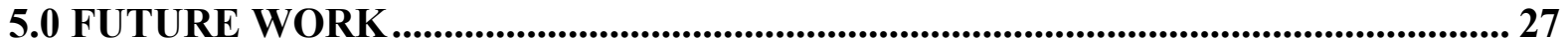

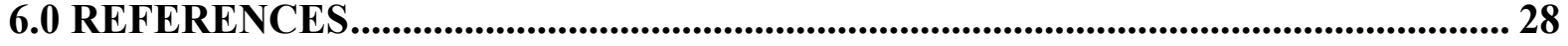

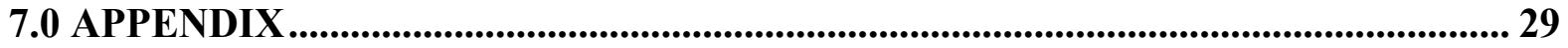

7.1 Strontium + manganese post filtration precipitate Chord length distribution data ...............................29

7.2 Strontium post filtration precipitate Chord length distribution data ....................................................... 30

7.3 Manganese post filtration precipitate Chord length distribution data .................................................... 31 


\section{LIST OF FIGURES}

Figure 4-1 FBRM chord length analysis of the baseline precipitation process 6

Figure 4-2 Chord length distribution of precipitate formed from caustic-adjusted AN-107 simulant. 7

Figure 4-3 Strontium solids chord length distribution versus time....................................... 10

Figure 4-5 Strontium slurry filtration rate versus precipitation reaction temperature ........... 12

Figure 4-6 Correlation between filtration rate and chord length population shifts for the strontium solids during temperature equilibration ...................................................... 13

Figure 4-7 Manganese precipitation DF versus added manganese....................................... 20

Figure 4-9 Manganese precipitation DF versus temperature .................................................. 20

Figure 4-11 Manganese precipitation percent removal vs. added manganese......................... 21

Figure 4-12 Manganese precipitation DF data versus time …………………………....... 25

Figure 4-13 Manganese precipitation DF data versus time semi-log plot ............................. 25

Figure 4-14 Total counts versus days for the formation of post-filtration precipitates .......... 27

\section{LIST OF TABLES}

Table 4-1 Analysis results for acid-digested solids from AN-107 simulant caustic adjustment

Table 4-2 Strontium precipitation test matrix and analysis results....................................... 9

Table 4-3 Chord length statistics for strontium solids before and after equilibration to $25^{\circ} \mathrm{C}$.

Table 4-4 Chord length statistics and filtration rate for added manganese versus temperature

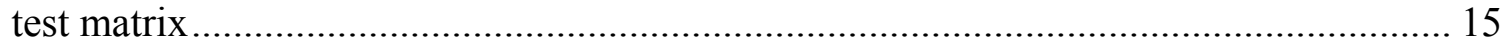

Table 4-5 ICP-ES analysis results of the acid-digested solids from selected tests................. 18

Table 4-6 Decontamination factors for added manganese versus temperature test matrix .... 19

Table 4-7 Percent removal for added manganese versus temperature test matrix.................. 19

Table 4-8 Chord length statistics and filtration rate for added manganese versus added hydroxide test matrix .................................................................................................... 22

Table 4-9 Decontamination factors for added manganese versus added hydroxide test matrix

Table 4-10 Percent removals for added manganese versus added hydroxide test matrix ...... 23

Table 4-11 Summary of post-filtration precipitation data after $\geq 3$ days storage .................... 26

\section{LIST OF ACRONYMS}

RPP-WTP River Protection Project - Waste Treatment Plant

FBRM Focused Beam Reflectance Method

DF Decontamination Factor

ICP-ES Inductively Coupled Plasma - Emission Spectroscopy

RCRA Resource Conservation and Recovery Act

NA Not available or Not applicable 


\subsection{EXECUTIVE SUMMARY}

Removal of radioactive strontium and transuranic elements from Hanford Envelope $\mathrm{C}$ waste solutions can be accomplished by the sequential addition of sodium hydroxide, strontium nitrate, and sodium permanganate solutions. This multistep precipitation process is the baseline technology in the River Protection Project -Waste Treatment Plant (RPP-WTP) for the removal of these radioactive species from Hanford Waste Tanks 241-AN-107 and 241AN-102. Decontamination targets are easily met using these precipitation technologies and current work in this area focuses on optimization to minimize reagent levels. Downstream treatment processes require filtration of the precipitate slurry. In order to avoid further precipitation after filtration, it is necessary to know the precipitation reaction time-scale. In addition, precipitate slurry filter flux is a primary parameter of interest to plant design personnel. Optimization of the filtration process is benefited by an understanding of the parameters that impact particle size distribution. Filter cake packing and, hence, filter flux are often sensitive to small changes in the particle size distribution. However, traditional methods of particle size analysis often are not sufficiently sensitive to develop correlations to filterability. Focused Beam Reflectance Measurements (FBRM) are a relatively new chord length analysis method with extremely high sensitivity. The method is suited for continuous monitoring of chord length distributions in the process medium. The instrument is equipped with statistical data analysis software for the identification of small shifts in the population. Reported herein are the results of FBRM analysis of strontium and manganese precipitation tests with Hanford AN-107 simulant.

\subsection{OBJECTIVES}

The objectives of the testing were to:

1) evaluate the impacts of precipitation parameters (temperature and reagent levels) upon the strontium and manganese particle chord length distributions

2) evaluate the stability of the particles under shear

3) determine the general time-scale of the precipitation reactions

4) identify correlations of the chord length distribution statistics to other measured experimental parameters such as slurry filterability

5) monitor the filtered samples for post-filtration precipitation in order to identify the parameters that lead to solids formation

\subsection{CONDUCT OF TESTING}

Chord length analysis of strontium and manganese precipitates formed from AN-107 simulant was accomplished using a Lasentec FBRM (Focused Beam Reflectance Measurement) chord length analyzer. The strontium and manganese precipitates were primarily studied independently using $130 \mathrm{~mL}$ of AN-107 simulant per test. Samples were monitored over a 4-hour period, filtered, and monitored for the presence of post-filtration solids over an extended time period. 


\subsection{RESULTS AND PERFORMANCE AGAINST OBJECTIVES}

Unique chord length distributions were obtained for strontium and manganese solids formed from AN-107 simulant. The impact of experimental parameters on the chord length distribution was determined and correlations were made to slurry filterability. General precipitation reaction times were determined under some experimental conditions. However, in other cases reaction times could not be determined from the chord length data due to complicating factors such as distribution changes induced by shear. The sensitivity of the particles to moderate shear was evaluated. The tendency of all samples to form postfiltration precipitates was evaluated.

\subsection{QUALITY REQUIREMENTS}

This work was conducted in accordance with the RPP-WTP QA requirements specified for work conducted by SRTC as identified in DOE IWO MOSRLE60. SRTC has provided matrices to WTP demonstrating compliance of the SRTC QA program with the requirements specified by WTP. Specific information regarding the compliance of the SRTC QA program with RW-0333P, Revision 10, NQA-1 1989, Part 1, Basic and Supplementary Requirements and NQA-2a 1990, Subpart 2.7 is contained in these matrices.

The work was conducted according to the QA requirements in Test Specification, TSPW375-01-00001, Rev. $0^{1}$ and Task Plan, WSRC-TR-2001-00261, Rev. $0^{2}$. This work was not required to comply with RW-0333P, Rev. 10. This work does comply with NQA-1 1989, Part 1, Basic and Supplementary Requirements and NQA-2a 1990, Subpart 2.7.

\subsection{ISSUES}

Discoveries of potential process significance in this work include:

1) potential negative impacts on slurry filterability resulting from filtration at temperatures higher than the precipitation tank temperature

2) potential negative impacts on slurry filterability resulting from precipitation with $<0.025$ $M$ added manganese

3) no lanthanide (and presumably no transuranic) decontamination without caustic adjustment

4) potential impacts on downstream ion exchange processing resulting from post-filtration precipitate formation within 1 day after filtration

\subsection{INTRODUCTION}

Precipitation technologies to remove radioactive strontium and transuranic elements from Hanford Envelope C waste tanks have been developed as part of the Hanford River Protection Project - Waste Treatment Plant (RPP-WTP) design. After caustic adjustment of the waste solution, non-radioactive strontium nitrate is added at levels above the solubility of strontium carbonate, resulting in precipitation of strontium solids. Radioactive strontium in 
the original waste sample is removed by isotopic dilution and precipitation with the bulk strontium solids. The strontium precipitation is followed by addition of sodium permanganate solution, which results in the formation of (presumably) $\mathrm{MnO}_{2}$ solids and coprecipitation of multivalent species, such as lanthanide and actinide ions from solution. Reduction of manganese likely involves numerous steps which include oxidation of organic species present in Envelope C waste.

Strontium and manganese precipitation tests were conducted with Envelope C Tank 241-AN107 simulant using an FBRM instrument. The method involves the measurement of particle chord lengths based on back scattered laser signal resulting from interactions with particles passing in front of the detector. The method is well suited for direct measurement of individual particles suspended in solution without sample isolation. The data must be carefully interpreted, due to the fact that the measured value is a chord length rather than a simple particle diameter. For a given particle, a number of different chords may be measured depending upon the presentation of the particle to the probe. The chord length distribution is a complex and unique fingerprint of the population that is impacted by particle size and shape (in contrast to traditional methods of particle size analysis that assume sphericity).

The strontium and manganese precipitation reactions were studied primarily independently, due to difficulties observed in analyzing the solids generated from one reaction in the presence of solids from the other. The strontium precipitation is considered to be a simple saturation phenomenon and is generally well-behaved and understood. Although numerous tests were conducted on the strontium precipitation, the primary focus of these studies was on the manganese solids, due to the expected complexity of this multi-step reactive precipitation. In addition, initial testing indicated that the manganese solids appear to have the primary influence on filterability (at least under the baseline conditions with moderate shear). Solids filterability and filtrate decontamination are primary properties of interest for the Envelope C precipitation process in the RPP-WTP. Furthermore, all tests in this study were conducted using filtered simulant containing no measurable entrained solids. The impact of the exclusion of entrained solids on the results is unknown.

\subsection{EXPERIMENTAL}

\subsubsection{Reagent and Simulant Preparations}

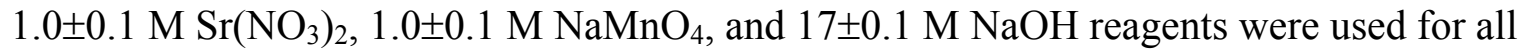
testing. All reagents were analyzed prior to use to confirm that the target concentrations were obtained and that the samples contained no solids. The sodium permanganate reagent was observed to form solids within several hours after preparation which were detectable by the chord length analyzer. Impacts of permanganate reagent decomposition upon the testing were minimized by: 1) preparing fresh reagent within 2-3 days prior to testing, 2) storing the reagent in the dark, and 3) filtering the reagent through a $0.45 \mu \mathrm{m}$ disposable nylon filter unit within 4 hours prior to use. The Hanford 241-AN-107 simulant was prepared according to procedures published by Eibling. ${ }^{3}$ The full simulant recipe was used including all RCRA hazardous components. All chemicals were reagent grade and the water used in the 
preparation had been passed through a Millipore water purification system. The simulant was prepared at a sodium concentration of $8.5 \mathrm{M}$ and then aged for at least one week prior to use. The simulant was diluted prior to precipitation testing to $6 \pm 0.1 \mathrm{M} \mathrm{Na}^{+}$by the addition of $0.01 \pm 0.001 \mathrm{M} \mathrm{NaOH}$ solution. The solution generally contained small amounts of solids even after dilution and aging. Within 12 hours prior to precipitation testing the simulant was filtered through a $0.45 \mu \mathrm{m}$ nylon Nalgene filter unit. Prior to each precipitation test the simulant was analyzed to confirm that no measurable solids were present.

\subsubsection{Instrumentation}

Chord length analysis was conducted using a Lasentec M400L Focused Beam Reflectance Analyzer. Samples were analyzed in a beaker $(\sim 500 \mathrm{~mL})$ positioned under the probe, such that the detector was immersed in the solution. Particles are presented to the probe with an impellor (4 blade, $45^{\circ}$ pitch, $1.5^{\prime \prime}$ diameter, axial upflow, 400 RPM) which introduces moderate shear effects to the system. The instrument response is a particle chord length distribution that can be updated every 2 seconds for continuous monitoring of changes in the distribution. A jacketed test beaker was prepared to allow for temperature control of the system during testing and was attached to a heating and cooling recirculator. A calibrated digital thermometer was suspended in the solution to monitor temperature. During analysis the beaker was covered with parafilm to minimize evaporation and exposure to the atmosphere. The stir rate used for testing did not result in air entrainment into the solution. The instrument was calibrated prior to use with standard polymer beads of well-known distribution.

\subsubsection{Test Procedure}

1. Attach the appropriate recirculator hoses to the jacketed test beaker and turn on the recirculator.

2. Filter the simulant and the permanganate reagent solutions.

3. Transfer $130 \mathrm{~mL}$ of filtered simulant to the jacketed test beaker.

4. Position the beaker under the FBRM measurement probe and turn on the impellor at a stir speed of 400 RPM.

5. Set the recirculator to the target temperature and cover the top of the beaker with parafilm.

6. Begin monitoring the sample at 2-minute scan intervals.

7. Once the sample reaches the target temperature (within $\pm 0.5^{\circ} \mathrm{C}$ ), transfer the appropriate amount of $17 \mathrm{M} \mathrm{NaOH}$ solution to the beaker. (Note: Unless otherwise indicated, all reagents were added in a single portion using a digital pipette.)

8. After 15 minutes add strontium reagent to the sample to give the desired concentration. Note: Skip this step if the test is to be conducted without strontium precipitation.

9. Monitor the sample continuously to track the distribution with time.

10. After 15 additional minutes add sodium permanganate reagent to give the desired concentration. Note: Skip this step if the test is to be conducted without manganese precipitation.

11. Continue monitoring the sample for the time specified by the researcher. 
12. Transfer the sample to a $250 \mathrm{~mL}$ polyethylene bottle and place the bottle in a water bath at the target reaction temperature used for the initial precipitation.

13. After 4 hours total reaction time (time zero = addition of first precipitating agent) transfer the slurry from the polyethylene bottle back to the jacketed beaker and monitor the sample as the temperature returns to $25 \pm 0.5^{\circ} \mathrm{C}$.

14. Immediately transfer the sample to a $0.45 \mu \mathrm{m}$ (nominal) filter unit attached to a diaphragm pump.

15. Turn on the pump for the time period specified by researcher at $\mathrm{P}=-20 \pm 1$ in $\mathrm{Hg}$. and measure the volume of filtrate collected.

16. Filter the sample a second time through a $0.1 \mu \mathrm{m}$ (nominal) nylon filter.

17. Collect samples of the filtrate for analysis.

18. Analyze the sample by FBRM to confirm that no detectable solids are present.

19. Return the sample to the plastic filter cup bottom and cap the filter cup.

20. Store the filtrate in the dark.

21. Measure the samples on the FBRM periodically over the next few weeks to monitor for post-filtration precipitate formation.

\subsection{DISCUSSION}

\subsection{STRONTIUM + MANGANESE PRECIPITATION TESTING}

The current baseline conditions for strontium and manganese precipitation of Hanford Envelope $\mathrm{C}$ waste samples includes (sequentially) caustic adjustment with sodium hydroxide solution, strontium precipitation with strontium nitrate solution, and manganese precipitation with sodium permanganate solution. Figure 4-1 shows the print screen output from FBRM chord length analysis of the baseline precipitation process. The left portion of the figure shows the chord length distribution at a selected time (in this case the measured distribution for the strontium solids is displayed). Total measured chords versus time are displayed in the right portion of the figure. An initial increase in total counts was observed immediately after addition of strontium nitrate solution to the simulant. A second large increase in counts was observed immediately after addition of sodium permanganate solution. Several precipitation tests were conducted prototypically as shown in Figure 4-1. However due to overlap of the strontium and manganese chord length distributions, it was difficult to accurately evaluate the chord length distribution of the manganese particles. In addition, ICP-ES (Inductively Couple Plasma - Emission Spectroscopy) analysis of the filtrate indicated that the two precipitation steps operated nearly independently with no evidence of synergistic impacts on the filtrate composition. These observations provided the basis to study the manganese precipitation independently without the preceding strontium precipitation. However, it should be noted that the presence of preformed strontium precipitate may impact the manganese precipitation step and the bulk of the tests in this study disregard this effect. Likewise, the impact of entrained solids upon both the strontium and manganese precipitation reactions was not studied. 
WSRC-TR-2002-00364, REV. 0-A

SRT-RPP-2002-00194. REV. 0-A

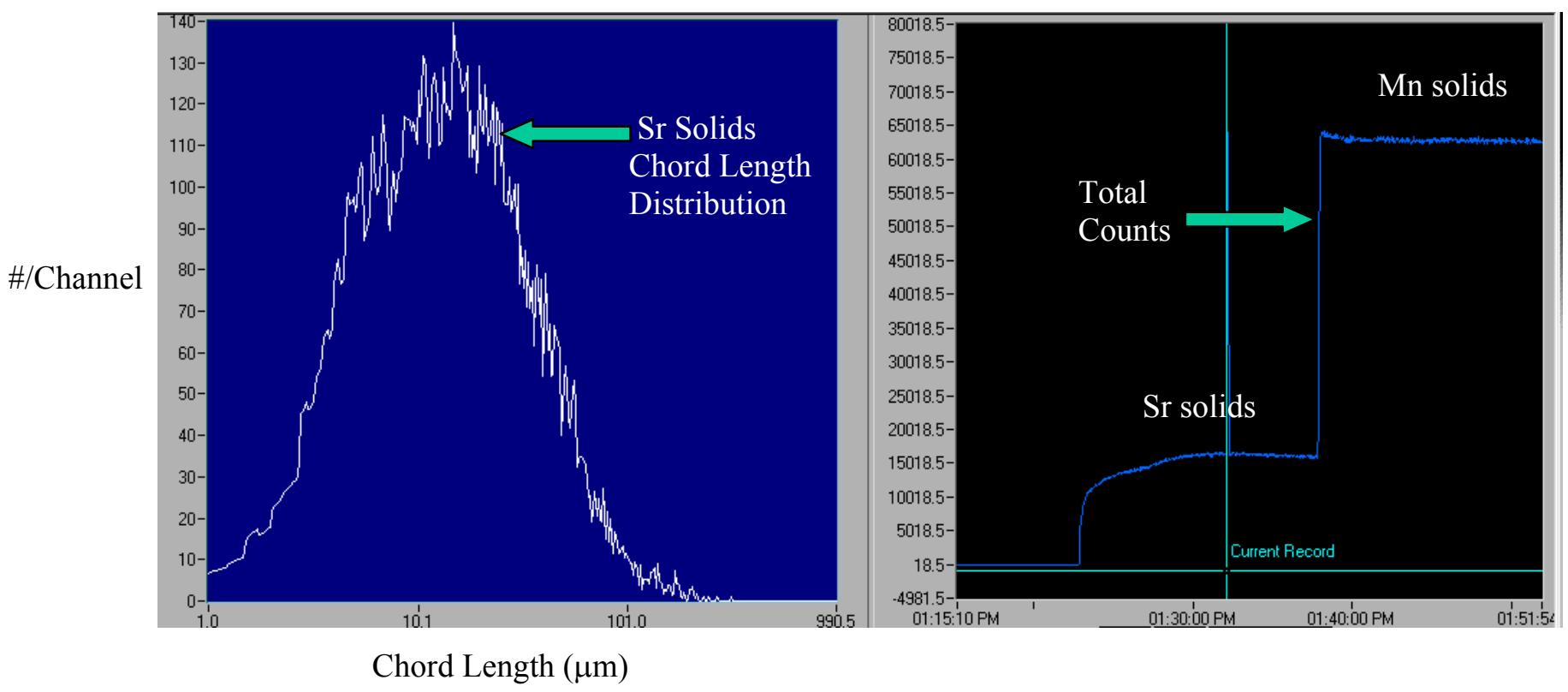

Figure 4-1 FBRM chord length analysis of the baseline precipitation process $\left(\mathrm{T}=50^{\circ} \mathrm{C}\right.$, 1.0 $\mathrm{M}$ added hydroxide, $0.075 \mathrm{M}$ added strontium, $0.05 \mathrm{M}$ added manganese) 


\subsection{PRECIPITATION FROM CAUSTIC SIMULANT ADJUSTMENT}

Chord length analysis of a sample of AN-107 simulant that had been adjusted to $1.0 \mathrm{M}$ added hydroxide at $50{ }^{\circ} \mathrm{C}$ revealed that caustic adjustment alone results in the formation of measurable solids within 1-2 hours. The measured chord length distribution for the solids is shown in Figure 4-2. It should be emphasized that the total counts measured during the fourhour reaction period was $<100$. At least with regard to total counts, the solids formed from caustic adjustment are not significant relative to the bulk precipitation. During storage at ambient temperature in the dark over a period of several weeks, brown solids were visually observed in the solution. The solids were filtered with a $0.45 \mu \mathrm{m}$ filter unit and washed several times with $0.01 \mathrm{M} \mathrm{NaOH}$. The sample was then digested in acid and analyzed by ICP-ES. Results are provided in Table 4-1. The solids contained significant amounts of manganese and iron at a molar ratio of 1.0: 0.87 , respectively. The primary interest in caustic-promoted precipitation is more likely the impact of caustic addition upon postfiltration precipitation, which will be discussed in later sections of the document. Caustic promoted precipitation has been observed before with actual AN-107 waste. ${ }^{4}$

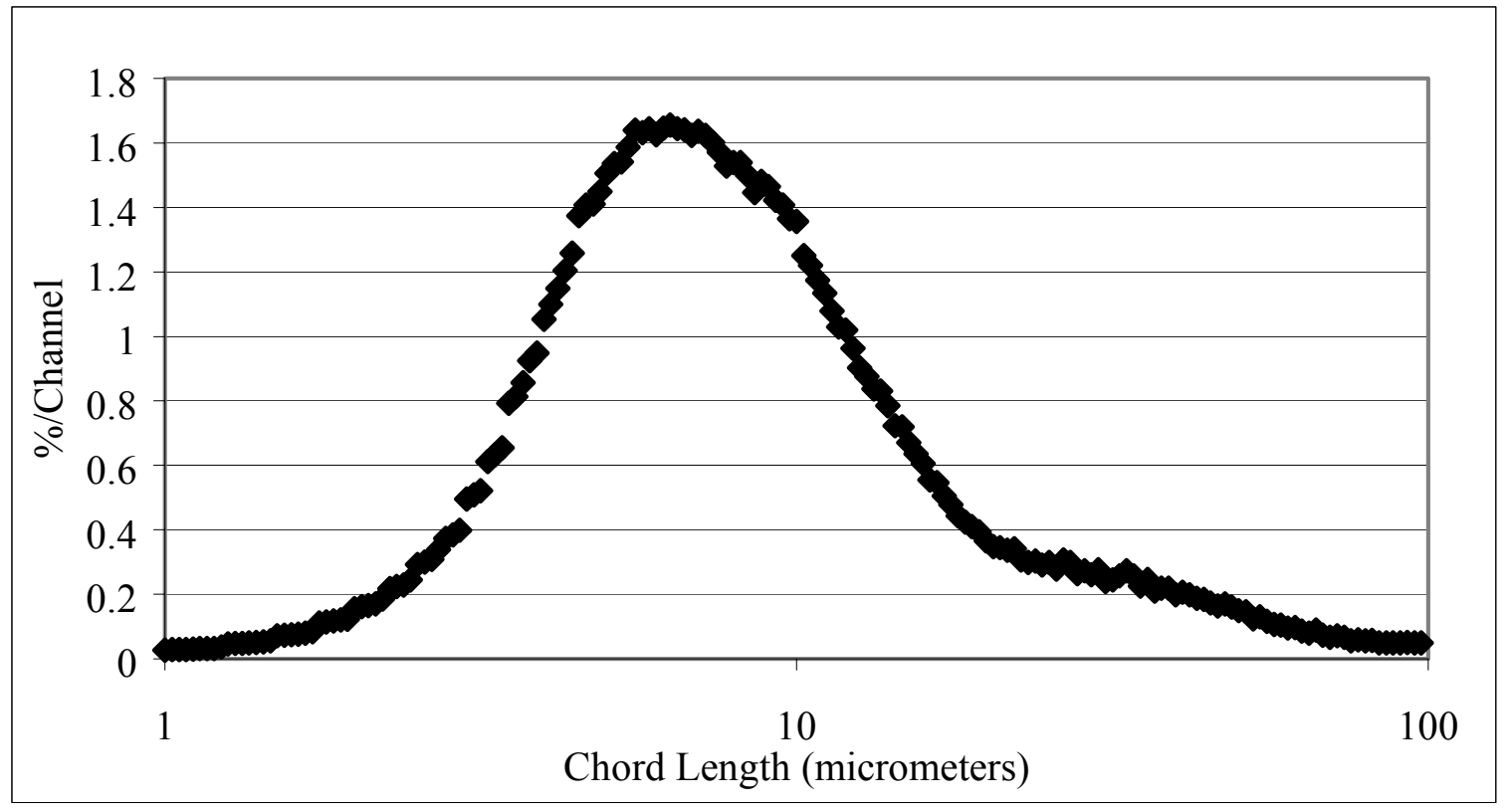

Figure 4-2 Chord length distribution of precipitate formed from caustic-adjusted AN107 simulant $\left(\mathrm{T}=50^{\circ} \mathrm{C}, 1.0 \mathrm{M}\right.$ added hydroxide $)$ 
Table 4-1 Analysis results for acid-digested solids from $\mathrm{AN}-107$ simulant caustic adjustment (1.0 M added hydroxide; major components indicated by bold type)

\begin{tabular}{|c|c|}
\multicolumn{1}{c}{ Analyte } & $\mu \mathrm{g} / \mathrm{g}$ in original solid \\
\hline $\mathrm{Al}$ & 3800 \\
\hline $\mathrm{B}$ & $<2500$ \\
\hline $\mathrm{Ba}$ & 917 \\
\hline $\mathbf{C a}$ & $\mathbf{1 5 9 0 0}$ \\
\hline $\mathrm{Cd}$ & $<200$ \\
\hline $\mathrm{Co}$ & $<500$ \\
\hline $\mathrm{Cr}$ & 1950 \\
\hline $\mathrm{Cu}$ & $<600$ \\
\hline $\mathbf{F e}$ & $\mathbf{1 7 6 0 0 0}$ \\
\hline $\mathrm{Li}$ & $<1200$ \\
\hline $\mathrm{Mg}$ & 1690 \\
\hline $\mathbf{M n}$ & $\mathbf{1 9 9 0 0 0}$ \\
\hline $\mathrm{Mo}$ & $<1200$ \\
\hline $\mathrm{Na}$ & $\mathrm{NA}$ \\
\hline $\mathrm{Ni}$ & 802 \\
\hline $\mathrm{P}$ & $<7800$ \\
\hline $\mathbf{P b}$ & $\mathbf{3 5 8 0 0}$ \\
\hline $\mathrm{Si}$ & $<3000$ \\
\hline $\mathrm{Sn}$ & $<300$ \\
\hline $\mathrm{Sr}$ & 484 \\
\hline $\mathrm{Ti}$ & $<1600$ \\
\hline $\mathrm{V}$ & $<1500$ \\
\hline $\mathrm{Zn}$ & $<4300$ \\
\hline $\mathrm{Zr}$ & $\mathrm{NA}$ \\
\hline $\mathrm{La}$ & $<8000$ \\
\hline $\mathbf{K}$ & $\mathbf{4 2 7 0 0}$ \\
\hline $\mathrm{Ce}$ & $<8800$ \\
\hline $\mathrm{Nd}$ & $<3000$ \\
\hline
\end{tabular}

*solids washed 2-3 times with $0.01 \mathrm{M} \mathrm{NaOH}$ prior to analysis

\subsection{STRONTIUM PRECIPITATION TESTING}

Strontium precipitation tests were conducted with AN-107 simulant varying sodium hydroxide and strontium nitrate reagent levels and temperature. Strontium solids were precipitated from solution presumably as strontium carbonate (based on data from previous studies $^{5-6}$ ) by the addition of $1.0 \mathrm{M}$ strontium nitrate solution. Baseline conditions for the strontium precipitation included: $\mathrm{T}=50{ }^{\circ} \mathrm{C}, 1.0 \mathrm{M}$ added hydroxide, and $0.075 \mathrm{M}$ added strontium. In all cases, caustic adjustment was conducted after temperature equilibration of the sample to the target value. Strontium reagent was added 15.0 minutes after caustic adjustment. Each reagent was added to the simulant in a single portion with a digital pipette. The solution was agitated with an impellor and continuously monitored for exactly 
Table 4-2 Strontium precipitation test matrix and analysis results

\begin{tabular}{|c|c|c|c|c|c|c|c|c|c|}
\hline Test & $\begin{array}{c}\text { Temp. } \\
\left({ }^{\circ} \mathrm{C}\right)\end{array}$ & $\begin{array}{c}\text { Added }\left[\mathrm{OH}^{-}\right] \\
(\mathrm{M})\end{array}$ & $\begin{array}{l}\text { Added [Sr] } \\
\text { (M) }\end{array}$ & $\begin{array}{c}\text { Total } \\
\text { Counts }^{\mathrm{a}} \\
\text { (chords } / \mathrm{sec} \text { ) }\end{array}$ & $\begin{array}{l}\text { Mean } \\
\text { Chord } \\
(\mu \mathrm{m})\end{array}$ & $\begin{array}{c}\text { Mean Sq. } \\
\text { Chord } \\
(\mu \mathrm{m})\end{array}$ & $\begin{array}{c}\text { Filtration } \\
\text { Rate }^{\text {b }} \\
(\mathrm{mL} / \mathrm{min})\end{array}$ & $\begin{array}{c}\text { Corrected } \\
\text { Filtrate }^{\mathrm{c}}[\mathrm{Sr}] \\
(\mathrm{mg} / \mathrm{L})\end{array}$ & $\begin{array}{c}\text { Average } \\
\text { Filtrate }[\mathrm{Sr}] \\
(\mathrm{mg} / \mathrm{L})\end{array}$ \\
\hline 1 & 50 & 0.2 & 0.075 & 20900 & 19 & 68 & 184 & 13.9 & \\
\hline 2 & 50 & 0.2 & 0.05 & 15100 & 20 & 81 & 140 & 13.2 & 13.2 \\
\hline 3 & 50 & 0.2 & 0.02 & 10000 & 22 & 80 & 160 & 12.4 & \\
\hline 4 & 50 & 1.0 & 0.075 & 21000 & 16 & 64 & 126 & 26.0 & \\
\hline 5 & 50 & 1.0 & 0.05 & $20200^{\mathrm{d}}$ & 13 & 62 & 128 & 21.6 & 22.5 \\
\hline 6 & 50 & 1.0 & 0.02 & 8500 & 18 & 71 & 142 & 19.8 & \\
\hline 7 & 25 & 1.0 & 0.075 & 10900 & 14 & 72 & 64 & 69.8 & \\
\hline 8 & 25 & 1.0 & 0.05 & 7000 & 12 & 73 & 60 & 81.9 & 75.8 \\
\hline 9 & 25 & 1.0 & 0.02 & 3900 & 16 & 108 & 36 & 75.6 & \\
\hline 10 & 15 & 1.0 & 0.075 & 8900 & 11 & 86 & 12 & 99.5 & \\
\hline 11 & 15 & 1.0 & 0.05 & 7000 & 16 & 84 & 12 & 94.5 & 95.1 \\
\hline 12 & 15 & 1.0 & 0.02 & 3500 & 19 & 101 & 28 & 91.2 & \\
\hline $4-R$ & 50 & 1.0 & 0.075 & $25500^{\mathrm{e}}$ & $15^{\mathrm{e}}$ & $61^{\mathrm{e}}$ & 91 & NA & \\
\hline
\end{tabular}

${ }^{a}$ Measured after equilibration to $25^{\circ} \mathrm{C}$ and just prior to filtration. Instrument response probably is not linear and total counts are impacted by sample shear history. Total counts are provided only to give a general idea of the amount of particles present.

${ }^{\mathrm{b}}$ Dead-end filtration with $0.45 \mu \mathrm{m}$ Nalgene nylon filter units (50 mm filter diameter) over a 0.5 -

minute time period.

${ }^{\mathrm{c}}$ Concentrations corrected for dilution due to reagent addition.

${ }^{\mathrm{d}}$ Higher than expected total counts for this sample could not be explained.

${ }^{\mathrm{e}}$ Distribution was obviously clipped at lower chord lengths, most likely resulting in an artificially low total counts value. Actual mean and mean squared were likely considerably smaller than reported.

30 minutes after strontium reagent addition, prior to being transferred to a polyethylene bottle that was tightly capped and placed in a water bath at the target temperature. Reaction was allowed to continue for 4 hours (after strontium reagent addition) before the slurry temperature was adjusted to $25^{\circ} \mathrm{C}$ while being analyzed by FBRM over a 30-minute time period.

The samples were then filtered through $0.45 \mu \mathrm{m}$ filters to determine filtration rates. Precipitation tests were also conducted at lower temperatures $\left(15\right.$ and $\left.25^{\circ} \mathrm{C}\right)$ and at $0.2 \mathrm{M}$ added hydroxide as shown in Table 4-2. The target added strontium concentrations studied were $0.02,0.05$, and $0.075 \mathrm{M}$ (theoretical $\mathrm{Sr}$ concentrations prior to precipitate formation). Statistical data (total measured counts, mean chord, and mean squared chord) calculated from chord length distributions collected after slurry equilibration to $25^{\circ} \mathrm{C}$ and just prior to filtration are shown in Table 4-2. The mean squared chord length is often representative of the spherical equivalent diameter that would be reported by traditional particle size analysis methods. Filtration rate data and "corrected" (for reagent dilution) strontium concentrations of the filtrate samples after the 4-hour reaction period are also provided. A constant filter time of 30 seconds was used for all samples for comparative purposes when determining 
WSRC-TR-2002-00364, REV. 0-A

SRT-RPP-2002-00194. REV. 0-A

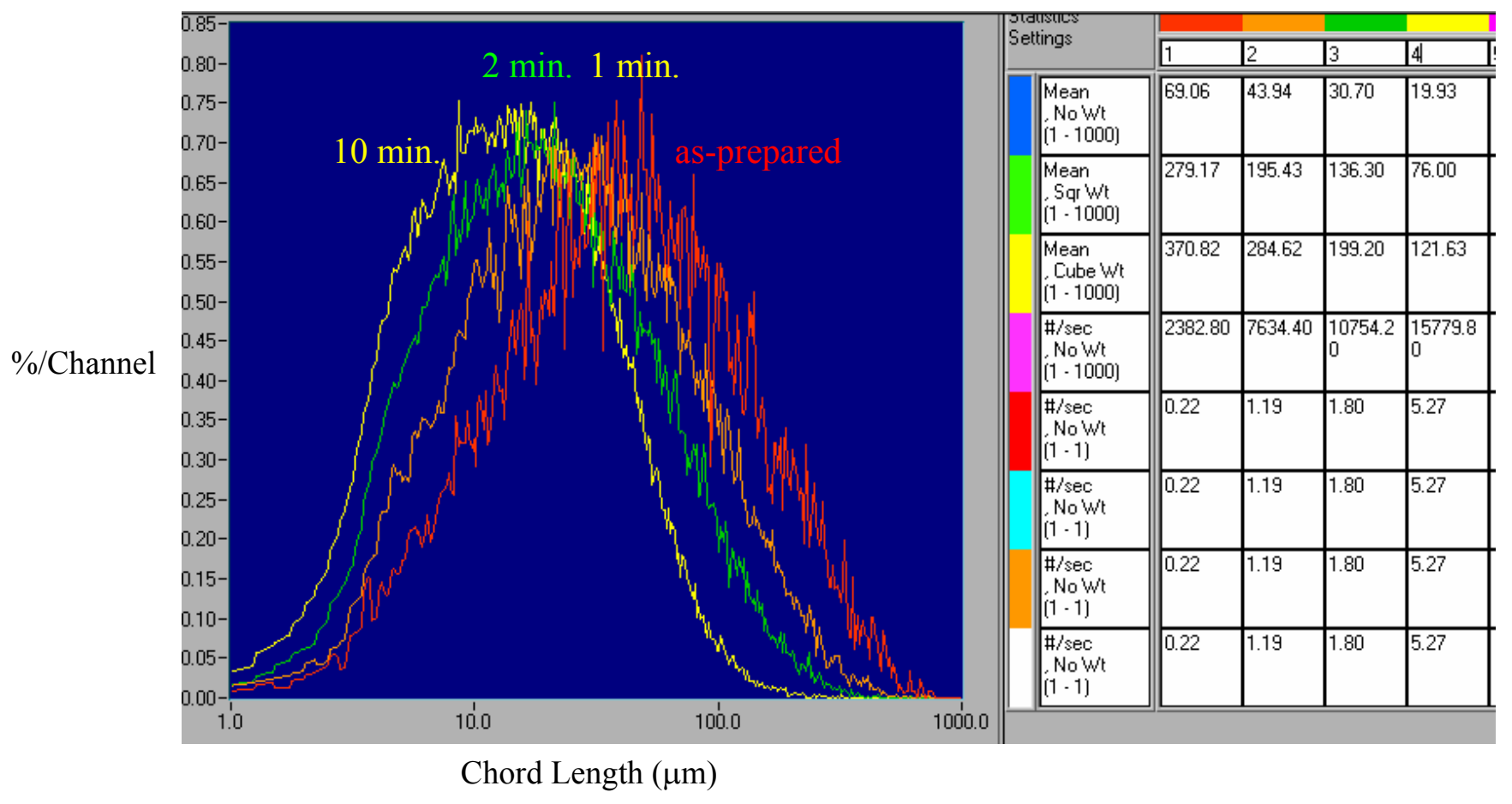

Figure 4-3 Strontium solids chord length distribution versus time $\left(\mathrm{T}=50^{\circ} \mathrm{C}, 1.0 \mathrm{M}\right.$ added hydroxide, $0.075 \mathrm{M}$ added strontium)

filtration rates. Longer filtration resulted in sample consumption prior to reaching the target measurement time, due to the rapid filtration rates observed for some samples.

The mean chord length of the strontium particles decreases rapidly when the particles are exposed to moderate shear (impellor blade at 400 RPM). Figure 4-3 is a print screen graphic from the FBRM software showing the changes in chord length distribution within the first 10 minutes after strontium reagent addition. The left portion of the figure shows the chord length distributions obtained after $0,1,2$, and 10 minutes. The distribution statistics for each time are shown to the right of the figure. The mean chord length decreases by $>70 \%$ within the first 10 minutes of agitation. Continuous agitation with the impellor during the 4-hour reaction period (4-R) results in further degradation such that the fine side of the chord length distribution is clipped due to the instrumental detection limit $(\sim 1 \mu \mathrm{m})$. For comparison, the distribution observed for the "as-prepared" particles indicated the presence of particles as large as $850 \mu \mathrm{m}$, versus $200 \mu \mathrm{m}$ for the continuously-agitated sample (4-R).

Increasing the added strontium from $0.02-0.075 \mathrm{M}$ at $50{ }^{\circ} \mathrm{C}$ generally results in predictable increases in the solids loading of the slurry (see total counts column, tests 1-6) except for test $\# 5$, for which the total counts were higher than expected. (Note: The total counts do not necessarily correspond directly to weight percent solids since instrument response may not be linear at this solids loading. However, the total count data can be used as a general measure of solids content.) This inconsistency could not be explained after reviewing the FBRM data 
collection file for this sample. Strontium concentrations in the filtrate solutions are somewhat constant at a given added hydroxide level and temperature, although there is a slight tendency toward higher strontium filtrate concentrations with higher added strontium. This indicates that some level of super saturation may have occurred as strontium reagent levels were increased. Average filtrate strontium concentrations were higher by a factor of 1.8 when the added hydroxide concentration was increased from 0.2 to $1.0 \mathrm{M}(13.2 \mathrm{vs.} 22.5$ $\mathrm{mg} / \mathrm{L}$ ), indicating that the strontium solids solubility increases with added hydroxide. Although the total counts observed were similar with 0.2 and $1.0 \mathrm{M}$ added hydroxide, the mean and mean squared statistics observed with $1.0 \mathrm{M}$ added hydroxide were 14 and $23 \%$ less (respectively) than the values observed with $0.2 \mathrm{M}$ added hydroxide. This indicates that the total mass of strontium solids produced at $1.0 \mathrm{M}$ added hydroxide is lower, which is consistent with the trends observed in the filtrate strontium concentrations.

Decreasing the reaction temperature from 50 to $15^{\circ} \mathrm{C}$ increased the average filtrate strontium concentration by a factor of 4 ( $23 \mathrm{vs} .95 \mathrm{mg} / \mathrm{L})$. Total particle counts decreased with decreasing temperature, although the mean squared chord length increased. The temperature dependence of the filtrate strontium concentration is consistent with the known retrograde solubility of strontium carbonate. The average filtrate strontium concentrations $(y)$ shown in Table 4-2 vary linearly with temperature (with $\mathrm{x}=\mathrm{T} ; \mathrm{y}=-2.09 \mathrm{x}+127 ; \mathrm{R}^{2}=0.9995$ ). Filtrate analysis data also indicates that strontium precipitation results in as much as $50 \%$ removal of calcium from AN-107 simulant. No significant removal of other metals, phosphorous, or sulfur was observed.

Filtration rates for the strontium solids produced at a reaction temperature of $50{ }^{\circ} \mathrm{C}$ were fast (range 120-190 $\mathrm{mL} / \mathrm{min}$ ) and did not show a strong correlation to added hydroxide or strontium reagent levels. Decreasing the precipitation reaction temperature to $15^{\circ} \mathrm{C}$ resulted in an $80-90 \%$ decrease in filter flux (at all added strontium reagent levels); even though the total solids content was lower at this reaction temperature and all samples were filtered at 25 ${ }^{\circ} \mathrm{C}$ (see Figure 4-4). Careful analysis of the chord length distribution statistics throughout the $25^{\circ} \mathrm{C}$ temperature equilibration period (following the 4-hour reaction time) reveals changes in the distributions that provide some insight into the dramatic dependence of filterability on reaction temperature. Table 4-3 provides additional chord length statistics for tests 4-12 and 4-R. "Before" and "after" designations in the table correspond, respectively, to the beginning and the end of the 30-minute temperature equilibration period for each sample. The "before" statistic corresponds 
WSRC-TR-2002-00364, REV. 0-A

SRT-RPP-2002-00194. REV. 0-A

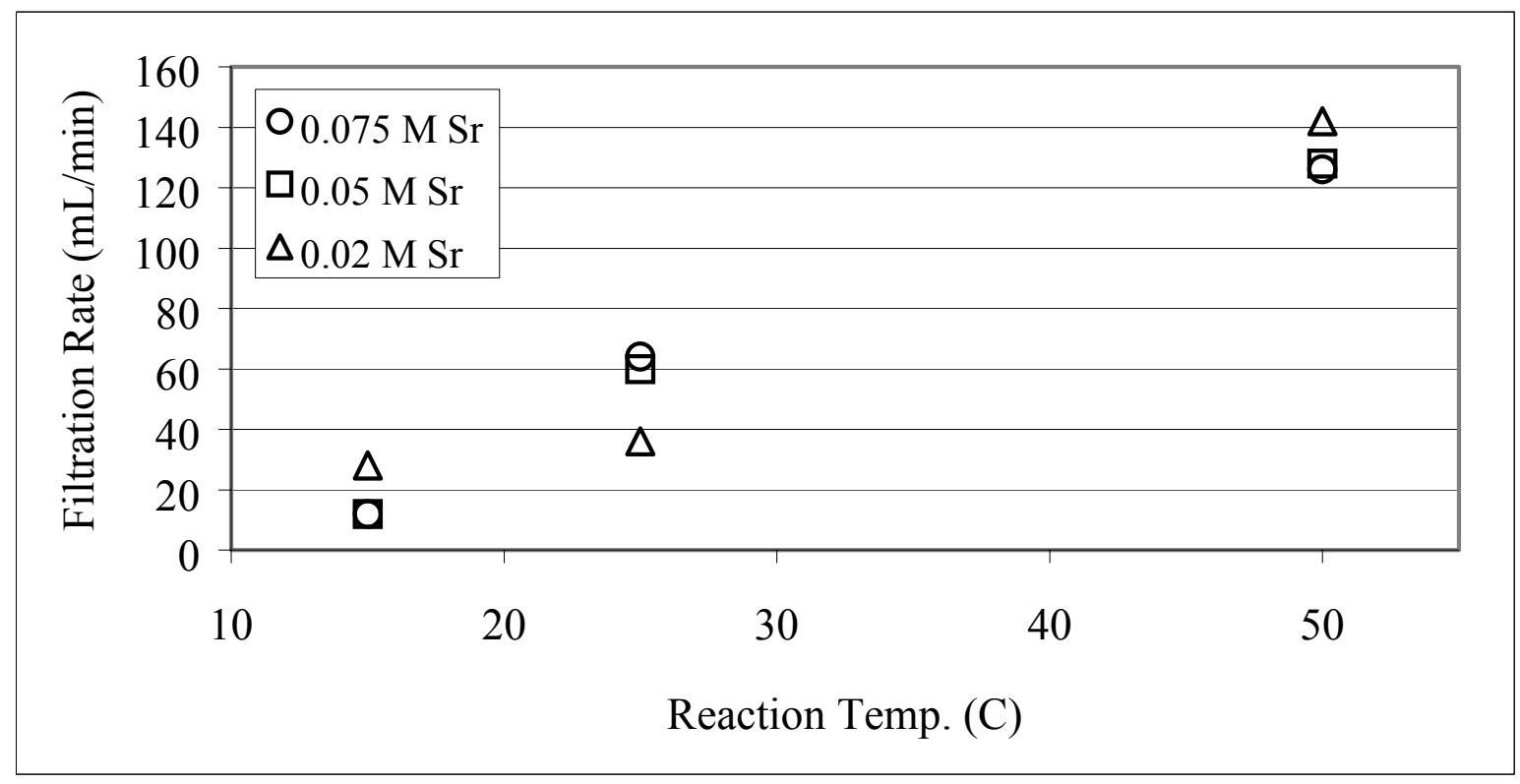

Figure 4-5 Strontium slurry filtration rate versus precipitation reaction temperature

to the distribution at the end of the 4-hour reaction period with the sample still at the precipitation reaction temperature indicated in the table. The "after" statistic corresponds to the distribution at the end of temperature equilibration to $25^{\circ} \mathrm{C}$, after exposure to 30 additional minutes of agitation with the impellor.

Statistics were chosen for comparison that were highly sensitive to the fine ( $\%$ less than 5 $\mu \mathrm{m}$ ) and coarse (\% greater than $25 \mu \mathrm{m}$ ) portions of the distributions, in order to identify population shifts that might explain the trends in filterability. The statistical trends are complicated by the continual shifts in the particle population with time resulting from shear. Since tests 7-9 were conducted at a reaction temperature of $25^{\circ} \mathrm{C}$, temperature was constant for the "before" and "after" measurement times. Therefore, changes in the distribution for this reaction temperature are solely the result of shear induced by agitation. As shown in the "average change" columns for tests 7-9, during the 30-minute temperature equilibration period the population shifts toward more fine (1.8 percentage point increase in the fraction less than $5 \mu \mathrm{m})$ and fewer coarse particles (1.5 percentage point decrease in the fraction greater than $25 \mu \mathrm{m})$. "Average change" values observed for the fine and coarse particles at $15{ }^{\circ} \mathrm{C}$ reaction temperature were identical in sign to the average statistics at $25^{\circ} \mathrm{C}$ but were larger in magnitude. This indicates that some process other than shear resulted in the generation of fine particles. At $50{ }^{\circ} \mathrm{C}$ reaction temperature the "average change" data indicates a shift in the distribution toward more coarse particles. The "average change" values for each temperature equilibration period are plotted versus slurry filtration rates in Figure 4-5.

The observed changes in the distributions are consistent with the known retrograde solubility of strontium carbonate. Decreasing the temperature from 50 to $25^{\circ} \mathrm{C}$ would be expected to 
WSRC-TR-2002-00364, REV. 0-A

SRT-RPP-2002-00194. REV. 0-A

Table 4-3 Chord length statistics for strontium solids before and after equilibration to $25{ }^{\circ} \mathrm{C}$.

Test Temp. Added [OH-] Added [Sr] before after

Average before after

Average

$\left({ }^{\circ} \mathrm{C}\right)$

(M)

$\%<5 \mu \mathrm{m} \%<5 \mu \mathrm{m}$

Change $\%>25$

$>25 \mu \mathrm{m}$ Change

Change

\begin{tabular}{|cccc|ccc|c|ccc|c|}
\hline 4 & 50 & 1.0 & 0.075 & 26.4 & 25.2 & -1.2 & & 17.7 & 18.2 & 0.5 & \\
5 & 50 & 1.0 & 0.05 & 28.2 & 27.9 & -0.3 & -0.7 & 12.8 & 12.9 & 0.1 & 0.5 \\
\hline 6 & 50 & 1.0 & 0.02 & 18.5 & 17.8 & -0.7 & & 22.0 & 23.0 & 1.0 & \\
\hline 7 & 25 & 1.0 & 0.075 & 27.1 & 28.8 & 1.7 & & 15.4 & 14.1 & -1.3 & \\
8 & 25 & 1.0 & 0.05 & 25.7 & 27.4 & 1.7 & 1.8 & 10.3 & 9.3 & -1 & -1.5 \\
\hline 9 & 25 & 1.0 & 0.02 & 10.8 & 12.9 & 2.1 & & 18.4 & 16.3 & -2.1 & \\
\hline 10 & 15 & 1.0 & 0.075 & 8.4 & 8.4 & 0.0 & & 13.4 & 7.5 & -5.9 & \\
11 & 15 & 1.0 & 0.05 & 12.8 & 16.8 & 4.0 & 4.4 & 22.5 & 17.7 & -4.8 & -4.4 \\
12 & 15 & 1.0 & 0.02 & 23.6 & 32.8 & 9.2 & & 26.6 & 24.2 & -2.4 & \\
\hline $4-\mathrm{R}$ & 50 & 1.0 & 0.075 & 58.1 & 42.1 & -16.0 & NA & 15.6 & 32.4 & 16.8 & NA \\
\hline
\end{tabular}

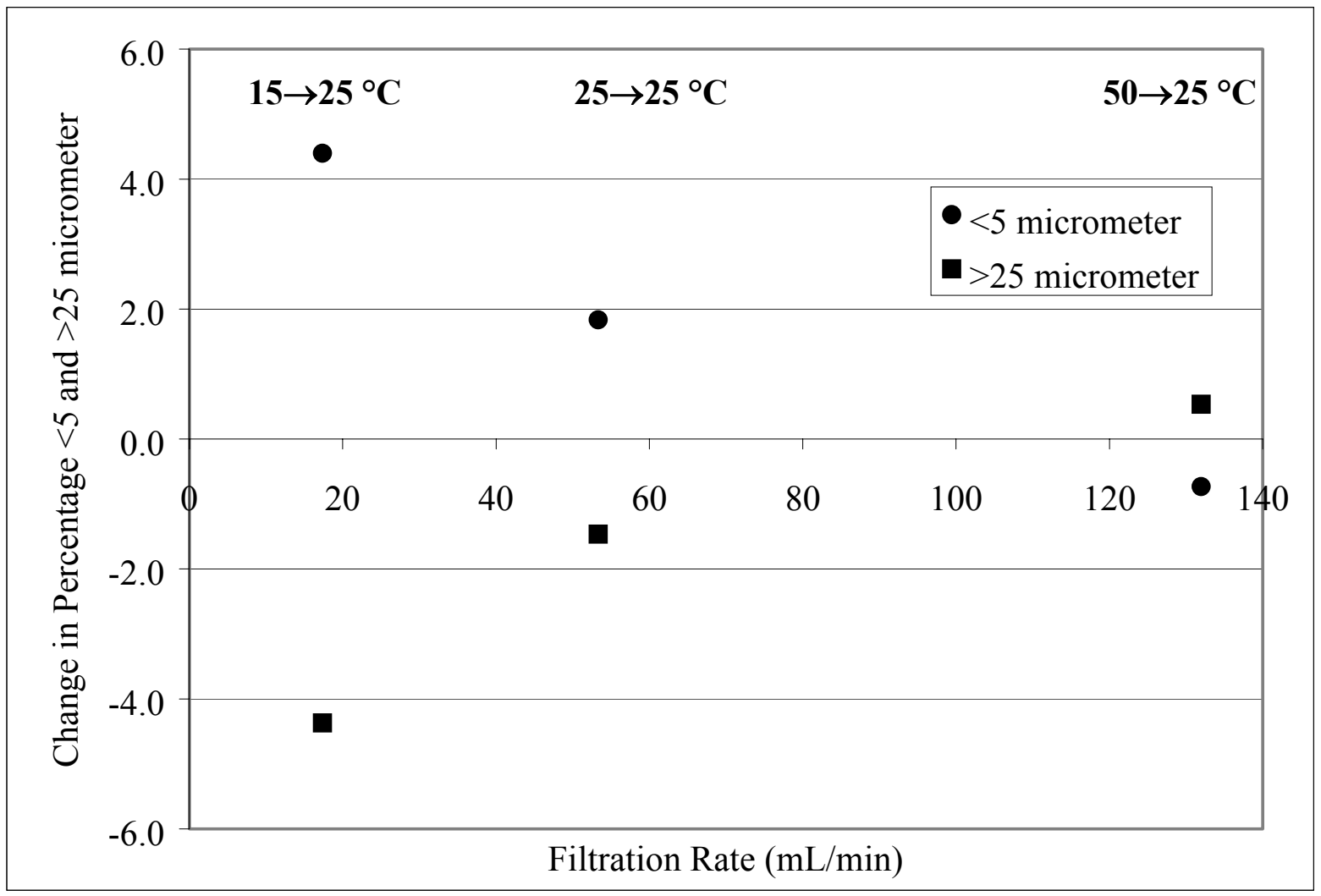

Figure 4-6 Correlation between filtration rate and chord length population shifts for the strontium solids during temperature equilibration (population shifts for the $25-25{ }^{\circ} \mathrm{C}$ transition result solely from shear during analysis) 
result in dissolution of fines and a shift in the population toward more coarse particles. This small population shift apparently leads to enhanced filterability. Conversely, increasing the temperature from 15 to $25^{\circ} \mathrm{C}$ results in generation of fines (probably as colloids) over and above those generated by shear, with a corresponding decrease in filterability. Dramatic changes in the distribution were observed for test 4-R during the temperature equilibration period. The measured fine chords $(<5 \mu \mathrm{m})$ decreased by 16.0 percentage points, while the coarse chords $(>25 \mu \mathrm{m})$ increased by 16.8 percentage points. These dramatic shifts in the distribution likely result from the large percentage of fine particles in this sample that was generated due to prolonged agitation. (Note: As mentioned previously, the chord length distribution for this sample was clipped on the fine side due to the instrumental detection limit.)

It should be noted that the mean and mean squared statistics before and after temperature equilibration did not change significantly for any sample. The observed trends in filterability could only be explained using statistics specifically chosen to respond to small changes in the fine and coarse ends of the chord length distribution. In all likelihood, no conventional analysis method could be used to detect these fine population shifts which correlate to measured filterabilities. The observation of significant filterability decreases resulting from filtration at temperatures higher than the precipitation reaction temperature could significantly impact plant filtration and temperature control protocols. Although additional work should be done to confirm that the trends observed for dead-end filtration of strontium solids translate to cross-flow filtration of combined strontium and manganese solids (which is currently the plant design filtration process).

Strontium precipitation reaction rates could not be determined from chord length analysis due to the strong influence of shear upon the distribution. However, one additional strontium precipitation test was conducted under the baseline conditions in which the slurry was filtered 10 minutes after strontium nitrate reagent addition. The filtrate was then analyzed continuously by FBRM during the remainder of the 4-hour reaction period. No significant counts were measured throughout the reaction period, indicating that under the baseline conditions strontium precipitation is complete within 10 minutes.

\subsection{MANGANESE PRECIPITATION TESTING}

Manganese precipitation from AN-107 simulant was promoted by the addition of $1.0 \mathrm{M}$ $\mathrm{NaMnO}_{4}$ reagent. Amorphous manganese oxide solids are formed by the oxidation of organic species in the simulant. Di- and tri-valent metals within the solution are removed by co-precipitation to the manganese solids. Baseline conditions for the manganese precipitation included: $\mathrm{T}=50{ }^{\circ} \mathrm{C}, 1.0 \mathrm{M}$ added hydroxide, and $0.05 \mathrm{M}$ added manganese. Tests were conducted without adding strontium reagent, although as stated earlier the presence of preformed strontium particles may impact the manganese precipitation. In all cases caustic simulant adjustment preceded manganese reagent addition by 30.0 minutes. Each reagent was added to the simulant in a single portion with a digital pipette. The solution was agitated with an impellor and continuously monitored for 15-20 minutes after manganese reagent addition prior to being transferred to a polyethylene bottle that was 
tightly capped and placed in a water bath. Reaction was allowed to continue for 4 hours (from manganese reagent addition time) before the slurry temperature was adjusted to $25^{\circ} \mathrm{C}$ and the sample was filtered. Precipitation tests were also conducted at lower temperatures $\left(15\right.$ and $\left.25^{\circ} \mathrm{C}\right)$ and at lower added hydroxide concentrations $(0.0,0.2$ and $0.5 \mathrm{M})$. The target added manganese concentrations studied were $0.01,0.025$, and $0.05 \mathrm{M}$ (theoretical $\mathrm{Mn}$ concentrations prior to precipitate formation).

Chord length distribution statistics, reaction time, and filtration rate data are provided in Table 4-4 for the added manganese versus temperature test matrix. Chord length distribution statistics were obtained from measurements at $25{ }^{\circ} \mathrm{C}$ just prior to filtration. However, chord length distribution for the manganese solids were generally not observed to change significantly after the first 15 minutes of reaction time or during the temperature equilibration period. As shown in Table 4-4, at added manganese reagent levels of 0.025 and $0.05 \mathrm{M}$ the chord length statistics are quite consistent and predictable. The mean and mean squared chord values at these reagent levels are $9 \pm 1$ and $21 \pm 2 \mu \mathrm{m}$, respectively, and do not vary with reaction temperature. Total counts increase with added manganese reagent levels and temperature, although the temperature dependence is small $(<20 \%$ total counts increase for $50{ }^{\circ} \mathrm{C}$ versus $15^{\circ} \mathrm{C}$ ). Given that particle size is constant, the fact that total counts were not observed to double when added manganese was increased from 0.025 to $0.05 \mathrm{M}$ indicates that instrument response is not linear at this solids loading.

At $0.01 \mathrm{M}$ added manganese, total counts were lower than expected and mean squared chord values were much larger for these samples. At 15 and $25^{\circ} \mathrm{C}$ the mean chord values are consistent with the tests conducted at higher manganese loadings. These observations indicate the presence of more coarse particles in the distribution which increase the weighted, but not the unweighted, mean. On a simple counting basis, the coarse particles are not significant in number relative to the entire population. However, on a mass basis the coarse particles are likely significant. At 15 and $25^{\circ} \mathrm{C}$, the small total counts observed with $0.01 \mathrm{M}$ added manganese might be explained by the presence of a relatively small number of coarse particles. However, this is not the case at $50^{\circ} \mathrm{C}$. The total counts value is very low for this sample, and although the mean and mean squared values are quite high, it seems unlikely that a comparable mass of solids was formed at this temperature than was formed at 15 and $25^{\circ} \mathrm{C}$ and $0.01 \mathrm{M}$ added manganese. Repetition of the test at $0.01 \mathrm{M}$ added manganese and $50^{\circ} \mathrm{C}$ gave similar counts and distribution 
WSRC-TR-2002-00364, REV. 0-A

SRT-RPP-2002-00194. REV. 0-A

Table 4-4 Chord length statistics and filtration rate for added manganese versus temperature test matrix (1.0 M added hydroxide)

\begin{tabular}{c|c|ccc|}
\multicolumn{1}{c}{} & \multicolumn{4}{c}{ Temperature $\left({ }^{\circ} \mathbf{C}\right)$} \\
Total Counts & Added Mn $(\mathrm{M})$ & 15 & 25 & 50 \\
\cline { 2 - 5 } (counts/sec.) & 0.05 & 55400 & 58000 & 60800 \\
& 0.025 & 34200 & 37000 & 40200 \\
Mean & 0.01 & 6700 & 6500 & 100 \\
\cline { 2 - 5 } (micrometers) & 0.05 & 9 & 8 & 8 \\
& 0.025 & 9 & 9 & 10 \\
Mean Squared & 0.01 & 9 & 8 & 28 \\
\cline { 2 - 5 } & 0.05 & 19 & 19 & 19 \\
& 0.025 & 19 & 20 & 23 \\
Reaction Time & 0.01 & 142 & 142 & 395 \\
\cline { 2 - 5 } (HH:MM:SS) & 0.05 & $0: 06: 08$ & $0: 01: 49$ & $0: 00: 48$ \\
& 0.025 & $0: 08: 48$ & $0: 06: 23$ & $0: 03: 24$ \\
Filtration & 0.01 & $0: 05: 40$ & $0: 01: 52$ & $0: 51: 34$ \\
\cline { 2 - 5 } Rate & 0.05 & $15-21^{\mathrm{c}}$ & $15-33^{\mathrm{c}}$ & 14.3 \\
(mL/min) & 0.025 & 12.8 & 12.6 & 12.0 \\
\cline { 2 - 5 } & 0.01 & 3.7 & 3.6 & $1.9^{\mathrm{d}}$ \\
\hline
\end{tabular}

${ }^{a}$ Instrument response probably is not linear. Total counts are provided only to give a general idea of the amount of particles present.

${ }^{\mathrm{b}}$ Dead-end filtration with $0.45 \mu \mathrm{m}$ Nalgene nylon filter units (50 mm filter diameter) over a 5-minute time period.

${ }^{\mathrm{c}}$ The entire sample volume was consumed before the end of the 5-minute filtration period. The upper value provided was calculated from the volume of filtrate collected after 3.5 minutes. The lower value is the calculated minimum filtration rate, assuming that the entire sample volume was filtered in exactly 5 minutes.

d This sample was exposed to 50 minutes additional agitation with the impellor in order to observe stabilization of total counts.

statistics. Separate tests in which small amounts of sodium permanganate reagent were added stepwise to AN-107 simulant adjusted to $1.0 \mathrm{M}$ added hydroxide indicated that a critical added manganese concentration is required to produce manganese solids. Due to the extreme sensitivity of the FBRM technique, it is not believed that the lack of measurable solids was an instrumental artifact. In addition, preformed $\mathrm{MnO}_{2}$ solids have been observed to dissolve in $\mathrm{AN}-107$ simulant with $1.0 \mathrm{M}$ added hydroxide.

Crude reaction times for solids formation were estimated by careful examination of the total count profile and other selected chord length statistics as a function of time for each experiment. Determination of general reaction times was possible due to the fact that the manganese chord length distribution does not change significantly due to agitation. This was 
not the case for the strontium solids, as discussed previously. At $0.05 \mathrm{M}$ added manganese, the reaction times followed the expected trends with higher temperatures resulting in shorter reaction times. For all manganese reagent levels and temperatures studied, solids formation appears to be complete in less than 10 minutes, except for the case where $\mathrm{T}=50^{\circ} \mathrm{C}$ and added manganese is $0.01 \mathrm{M}$. For this test, the total counts were so low that the reaction time data probably is not highly meaningful. In order to confirm that manganese solids formation is complete within 10 minutes, an additional test was conducted under the baseline conditions, but the sample was filtered 10 minutes after initial precipitation. The filtrate was then continually monitored by FBRM during the standard 4-hour reaction period. No significant solids were detected throughout the reaction period, confirming that under the baseline conditions, manganese solids formation is completed within 10 minutes.

5-minute filtration rates for the manganese precipitate slurries after temperature stabilization to $25^{\circ} \mathrm{C}$ are generally low relative to strontium precipitate slurry filtration. (Note: This is a general statement. Direct comparison of filtration rate data between Tables 4-2 and 4-4 is not possible since the chosen filtration measurement times for the two types of solids were different.) With added manganese reagent levels of $0.025-0.05 \mathrm{M}$, moderate filtration rates were observed $(12-33 \mathrm{~mL} / \mathrm{min})$. Filterability decreases considerably with $0.01 \mathrm{M}$ added manganese to $<4 \mathrm{~mL} / \mathrm{min}$, despite the fact that the total solids loading is much lower for these samples. Analysis results of the acid-digested manganese solids generated from several samples provide a potential explanation for the low filtration rates observed at $0.01 \mathrm{M}$ added manganese. Analysis results are shown in Table 4-5 for solids generated from 0.05 and 0.01 $\mathrm{M}$ added manganese at $50^{\circ} \mathrm{C}$ and $1.0 \mathrm{M}$ added hydroxide. In both cases the solids contain significant amounts of manganese and iron. However, comparison of the Fe:Mn molar ratios for these samples reveals that solids formed with $0.01 \mathrm{M}$ added manganese are enriched in iron by a factor of approximately 2.5 relative to the solids formed with $0.05 \mathrm{M}$ added manganese. This compositional change may explain the poor filterability as well as the larger mean squared chord of the solids with $0.01 \mathrm{M}$ added manganese. Poor filterability of iron precipitates has been observed previously with Hanford Envelope $\mathrm{C}$ waste. It should also be noted that the manganese solids composition, precipitation reaction time scale, and distribution statistics observed at $50{ }^{\circ} \mathrm{C}$ and $0.01 \mathrm{M}$ added manganese are characteristic of the solids formed from caustic-promoted precipitation of AN-107 simulant discussed in section 2.2 .

Decontamination factor and \% removal data for selected metals in the filtrate samples from the manganese versus temperature test matrix are shown in Tables 4-6 and 4-7, respectively. All data has been corrected for sample dilution resulting from reagent addition. Significant removal of manganese, iron, and lanthanides is observed for all samples at all temperatures with $\geq 0.025 \mathrm{M}$ added manganese, with the maximum removal (85-95\%) being observed under the baseline conditions. La, $\mathrm{Ce}$, and $\mathrm{Nd}$ removal is of interest in that these species may serve as surrogates for the transuranic elements in actual tank waste. As shown in Figures 46 and 4-7, DF data for all species vary linearly with respect to added manganese reagent level and temperature. Less than $50 \%$ removal is observed for all species at all temperatures with $0.01 \mathrm{M}$ added manganese. Interestingly, the DF data for all species except manganese increase with temperature (Figure $4-7)$. The manganese DF data is near 7 ( $85 \%$ removal) 
Table 4-5 ICP-ES analysis results of the acid-digested solids from selected tests (major components indicated by bold type)

\begin{tabular}{|c|c|c|c|}
\hline Reaction Temp. $\left({ }^{\circ} \mathrm{C}\right)$ & 50 & 50 & 50 \\
\hline Added $\mathrm{OH}^{-}(\mathrm{M})$ & 1.0 & 1.0 & 0.0 \\
\hline Added Mn (M) & 0.01 & 0.05 & 0.05 \\
\hline \multicolumn{4}{|c|}{$\mu \mathrm{g} / \mathrm{g}$ in original solid } \\
\hline Al & 2700 & 726 & 4610 \\
\hline $\mathrm{B}$ & $<1200$ & $<550$ & 770 \\
\hline $\mathrm{Ba}$ & 203 & 45 & 35 \\
\hline $\mathrm{Ca}$ & 9870 & 5060 & 5270 \\
\hline $\mathrm{Cd}$ & $<70$ & $<50$ & $<50$ \\
\hline Co & $<250$ & $<50$ & $<50$ \\
\hline $\mathrm{Cr}$ & 2890 & 1530 & 2450 \\
\hline $\mathrm{Cu}$ & 270 & 413 & 74 \\
\hline $\mathbf{F e}$ & 152000 & 84600 & 79300 \\
\hline $\mathrm{Li}$ & $<500$ & $<100$ & $<100$ \\
\hline $\mathrm{Mg}$ & 1930 & 1160 & 826 \\
\hline Mn & 190000 & 250000 & 273000 \\
\hline Mo & $<500$ & $<100$ & $<100$ \\
\hline $\mathrm{Na}$ & NA & NA & NA \\
\hline $\mathrm{Ni}$ & 413 & 330 & 192 \\
\hline $\mathrm{P}$ & $<3500$ & $<700$ & $<1500$ \\
\hline $\mathrm{Pb}$ & 33700 & 17440 & 9220 \\
\hline $\mathrm{Si}$ & $<1100$ & $<500$ & $<500$ \\
\hline $\mathrm{Sn}$ & $<300$ & $<300$ & $<300$ \\
\hline $\mathrm{Sr}$ & 312 & 131 & 152 \\
\hline $\mathrm{Ti}$ & $<700$ & $<150$ & $<150$ \\
\hline $\mathrm{V}$ & $<650$ & $<150$ & $<150$ \\
\hline $\mathrm{Zn}$ & $<1850$ & 614 & $<350$ \\
\hline $\mathrm{Zr}$ & NA & NA & NA \\
\hline $\mathrm{La}$ & 3710 & 1880 & 1450 \\
\hline $\mathrm{K}$ & 15500 & 3300 & 3270 \\
\hline $\mathrm{Ce}$ & $<3800$ & 1650 & 1190 \\
\hline $\mathrm{Nd}$ & 2190 & 3130 & 2190 \\
\hline Fe/Mn Mole Ratio & 0.79 & 0.33 & 0.29 \\
\hline
\end{tabular}

*solids washed 2-3 times with $0.01 \mathrm{M} \mathrm{NaOH}$ prior to analysis 
Table 4-6 Decontamination factors for added manganese versus temperature test matrix (1.0 $\mathrm{M}$ added hydroxide)

\begin{tabular}{|c|c|c|c|c|c|c|}
\hline \multirow[b]{2}{*}{ Added Mn (M) } & \multicolumn{6}{|c|}{ DF Data* } \\
\hline & $\mathrm{T}\left({ }^{\circ} \mathrm{C}\right)$ & Mn & $\mathrm{Fe}$ & $\mathrm{La}$ & $\mathrm{Ce}$ & $\mathrm{Nd}$ \\
\hline 0.05 & 15 & 6.6 & 3.9 & 6.3 & 5.6 & 4.4 \\
\hline 0.025 & 15 & 3.6 & 2.2 & 3.7 & 2.8 & 2.1 \\
\hline 0.01 & 15 & 1.7 & 1.6 & 2.0 & 1.7 & 1.4 \\
\hline 0.05 & 25 & 6.7 & 5.6 & 9.3 & 6.6 & 5.7 \\
\hline 0.025 & 25 & NA & NA & NA & NA & NA \\
\hline 0.01 & 25 & 1.5 & 1.6 & 1.9 & 1.4 & 1.3 \\
\hline 0.05 & 50 & 7.0 & 13.4 & 16.8 & 11.7 & 12.4 \\
\hline 0.025 & 50 & 3.0 & 4.1 & 5.9 & 4.9 & 3.6 \\
\hline 0.01 & 50 & 1.1 & 1.7 & 1.9 & 1.7 & 1.4 \\
\hline
\end{tabular}

* corrected for sample dilution resulting from reagent addition

Table 4-7 Percent removal for added manganese versus temperature test matrix (1.0 M added hydroxide)

\begin{tabular}{|c|c|c|c|c|c|c|}
\hline \multirow[b]{2}{*}{ Added Mn (M) } & \multicolumn{5}{|c|}{ \% Removal* } & \multirow[b]{2}{*}{$\mathrm{Nd}$} \\
\hline & $\mathrm{T}\left({ }^{\circ} \mathrm{C}\right)$ & $\mathrm{Mn}$ & $\mathrm{Fe}$ & $\mathrm{La}$ & $\mathrm{Ce}$ & \\
\hline 0.05 & 15 & 85 & 74 & 84 & 82 & 77 \\
\hline 0.025 & 15 & 72 & 54 & 73 & 65 & 53 \\
\hline 0.01 & 15 & 42 & 37 & 51 & 39 & 30 \\
\hline 0.05 & 25 & 85 & 82 & 89 & 85 & 82 \\
\hline 0.025 & 25 & NA & NA & NA & NA & NA \\
\hline 0.01 & 25 & 34 & 36 & 47 & 30 & 25 \\
\hline 0.05 & 50 & 86 & 93 & 94 & 91 & 92 \\
\hline 0.025 & 50 & 67 & 75 & 83 & 79 & 72 \\
\hline 0.01 & 50 & 12 & 41 & 47 & 41 & 30 \\
\hline
\end{tabular}

* corrected for sample dilution resulting from reagent addition 
WSRC-TR-2002-00364, REV. 0-A

SRT-RPP-2002-00194. REV. 0-A

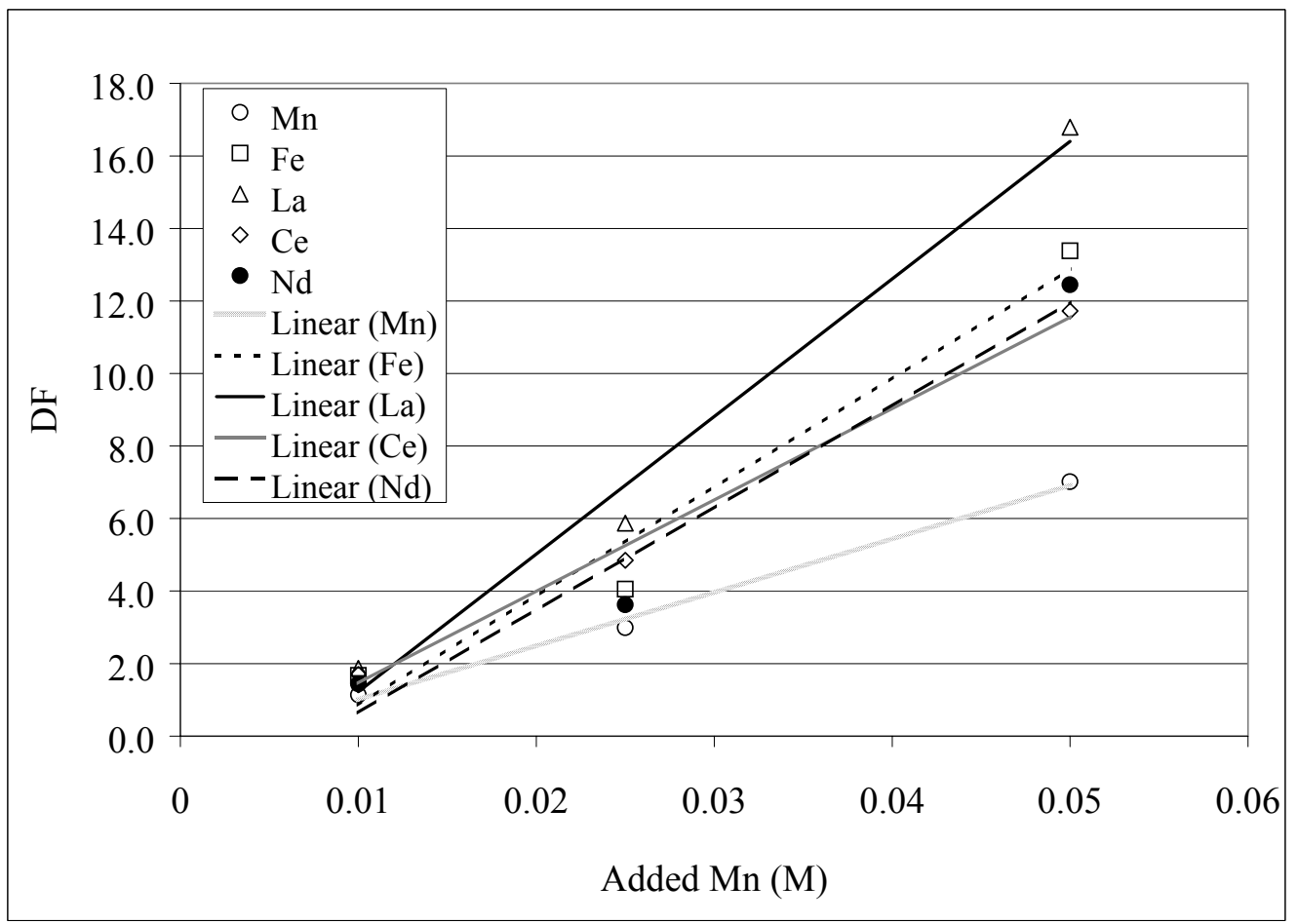

Figure 4-7 Manganese precipitation DF versus added manganese $\left(\mathrm{T}=50^{\circ} \mathrm{C}, 1.0 \mathrm{M}\right.$ added hydroxide)

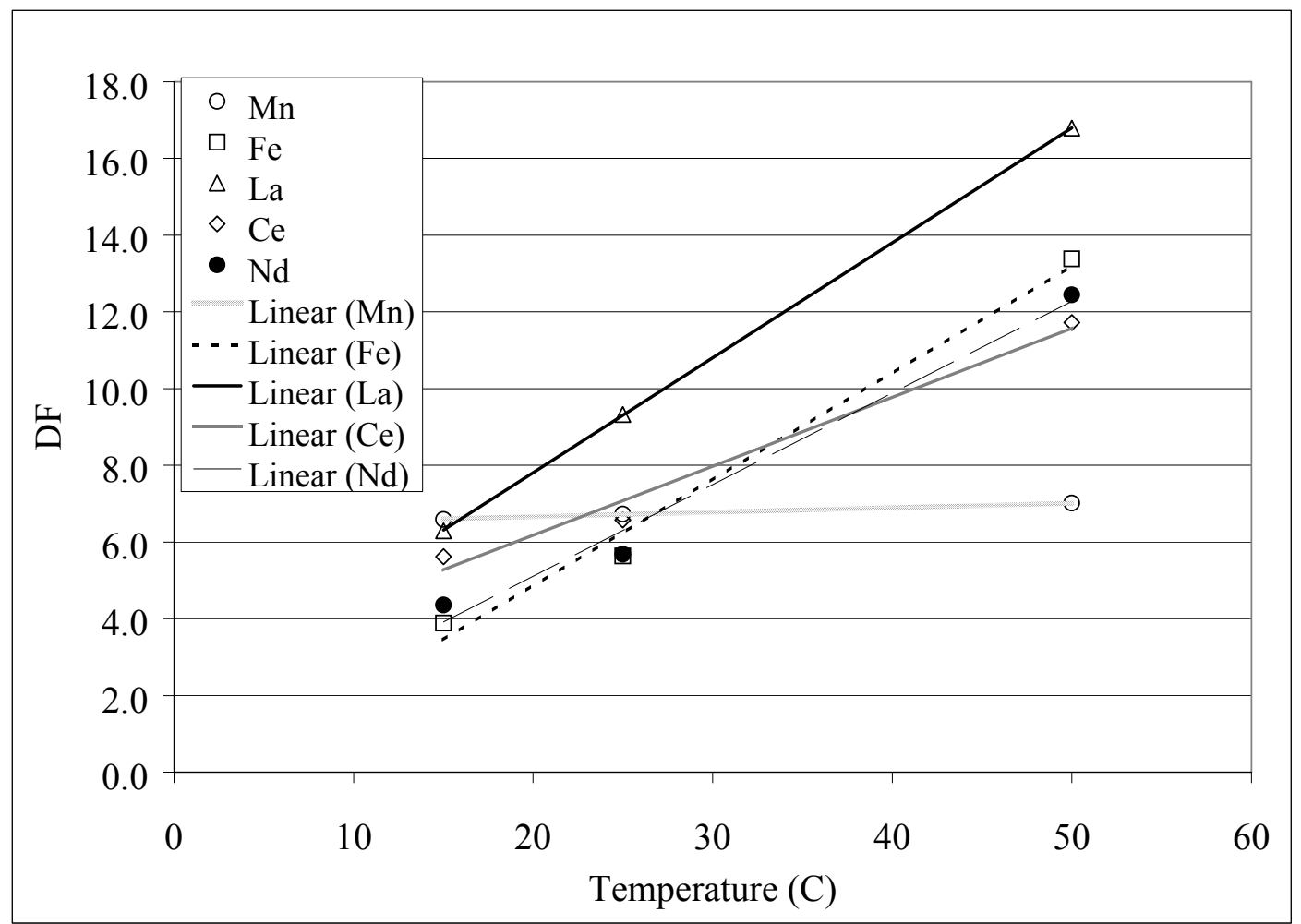

Figure 4-9 Manganese precipitation DF versus temperature (1.0 M added hydroxide, $0.05 \mathrm{M}$ added manganese) 


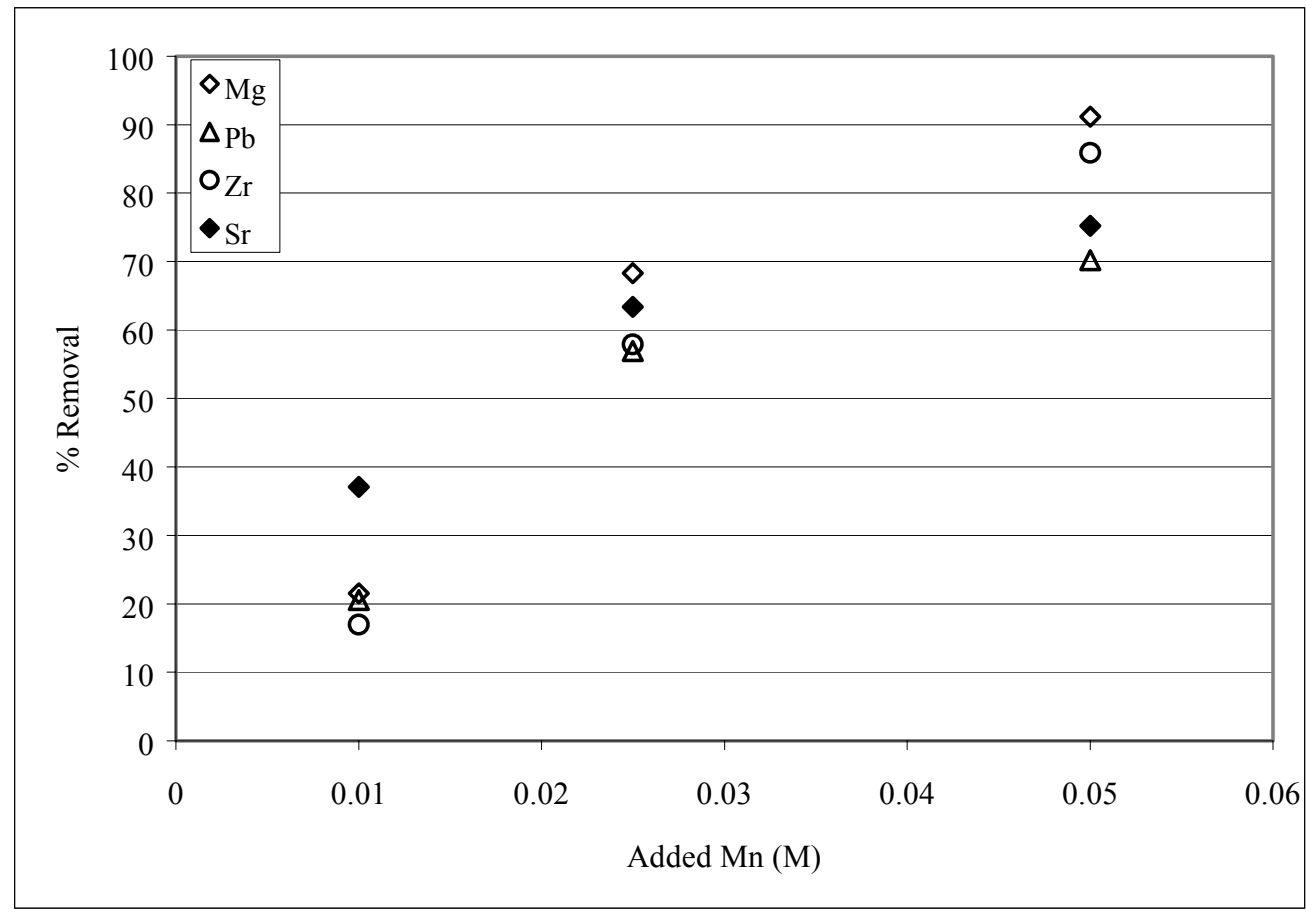

Figure 4-11 Manganese precipitation percent removal vs. added manganese $\left(\mathrm{T}=50{ }^{\circ} \mathrm{C}, 1.0\right.$ $M$ added hydroxide)

for all temperatures. This observation indicates that the mechanism of manganese removal from AN-107 simulant differs from the removal mechanism for iron and the lanthanides. As shown in Figure 4-8, significant removal of $\mathrm{Mg}, \mathrm{Pb}, \mathrm{Zr}$, and $\mathrm{Sr}$ is also observed. \% removal values of these species increased from 20 to $90 \%$ as the added manganese reagent level was increased from 0.01 to $0.05 \mathrm{M}$.

Table 4-8 provides chord length distribution statistics and filtration rate data for the added manganese versus added hydroxide test matrix. Distribution statistics were obtained from measurements at $25{ }^{\circ} \mathrm{C}$ just prior to filtration. At added manganese reagent levels of 0.025 and $0.05 \mathrm{M}$ and 0.2-1.0 $\mathrm{M}$ added hydroxide, the chord length statistics are quite consistent and predictable. The mean and mean squared chord values at these reagent levels are $9 \pm 1$ and $21 \pm 2$ $\mu \mathrm{m}$, respectively, as was observed for the added manganese versus temperature test matrix. Total counts increase with added manganese reagent levels and added hydroxide. Total counts increased an average of $19 \%$ at these manganese reagent levels $(0.025$ and $0.05 \mathrm{M})$ as the added hydroxide was increased from 0.2 to $1.0 \mathrm{M}$. As discussed earlier, the total counts data indicates that instrument response is not linear at this solid loading. $0.01 \mathrm{M}$ added manganese results in lower than expected total counts at added hydroxide levels ranging from 0.2-1.0 M. Mean squared chord data for these samples are high, as was observed for the manganese versus temperature test matrix. The chord length distribution statistics observed with no added hydroxide were markedly different than those observed for caustic-adjusted simulant. Total counts were lower while mean and mean squared chord length statistics were higher. 
Filtration rates varied considerably across the test matrix, making the identification of trends in the data difficult. Filtration variability was likely impacted by differences in ionic strength and viscosity resulting from reagent additions. This variability in the samples was not present in the added manganese versus temperature test matrix since reagent additions were identical for all samples. The highest filtration rates in Table $4-8$ were observed at $50{ }^{\circ} \mathrm{C}$ with $1.0 \mathrm{M}$ added hydroxide and $0.025-0.05 \mathrm{M}$ added manganese. The lowest filtration rates were observed with $0.01 \mathrm{M}$ added manganese and caustic-adjusted simulant.

DF data and \% removal for the added manganese versus added hydroxide test matrix are shown in Tables 4-9 and 4-10, respectively. At added hydroxide levels $\geq 0.2 \mathrm{M}$, filtrate decontamination appears to be independent of hydroxide reagent level. Little decontamination was observed at $0.01 \mathrm{M}$ added manganese, regardless of added hydroxide level. Despite the fact that significant solids were observed for the samples with no added hydroxide, very little decontamination was observed, even with $0.05 \mathrm{M}$ added manganese. This indicates that caustic adjustment is critical to promote removal of lanthanides from solution. Based on analysis of acid-digested solids in Table 4-5, at $0.05 \mathrm{M}$ added manganese the bulk solids composition does not vary significantly with added hydroxide levels of 0.0 and $1.0 \mathrm{M}$.

Table 4-8 Chord length statistics and filtration rate for added manganese versus added hydroxide test matrix $\left(\mathrm{T}=50^{\circ} \mathrm{C}\right)$

\begin{tabular}{|c|c|c|c|c|c|}
\hline & \multicolumn{5}{|c|}{ Added Hydroxide } \\
\hline & Added Mn (M) & $0.0 \mathrm{M}$ & $0.2 \mathrm{M}$ & $0.5 \mathrm{M}$ & $1.0 \mathrm{M}$ \\
\hline Total Counts ${ }^{\mathrm{a}}$ & 0.05 & 19700 & 49700 & 57600 & 60800 \\
\hline (counts/sec.) & 0.025 & 12700 & 34300 & 42400 & 40200 \\
\hline & 0.01 & 6600 & 11400 & 10700 & 100 \\
\hline Mean & 0.05 & 15 & 9 & 8 & 8 \\
\hline (micrometers) & 0.025 & 16 & 10 & 10 & 10 \\
\hline & 0.01 & 9 & 10 & 9 & 26 \\
\hline Mean Squared & 0.05 & 39 & 21 & 20 & 19 \\
\hline & 0.025 & 38 & 22 & 22 & 23 \\
\hline & 0.01 & 73 & 46 & 64 & 337 \\
\hline Filtration & 0.05 & 6.9 & 5.1 & --- & 14.3 \\
\hline Rate $^{b}$ & 0.025 & 3.3 & 9.1 & --- & 12.0 \\
\hline$(\mathrm{mL} / \mathrm{min})$ & 0.01 & $10.6^{\mathrm{c}}$ & $2.9^{\mathrm{c}}$ & --- & $1.9^{\mathrm{c}}$ \\
\hline
\end{tabular}

${ }^{a}$ Instrument response probably is not linear. Total counts are provided only to give a general idea of the amount of particles present.

${ }^{\mathrm{b}}$ Dead-end filtration with $0.45 \mu \mathrm{m}$ Nalgene nylon filter units (50 mm filter diameter) over a 5-minute time period.

${ }^{\mathrm{c}}$ These samples were exposed to 30-50 minutes additional agitation with the impellor. 
WSRC-TR-2002-00364, REV. 0-A

SRT-RPP-2002-00194. REV. 0-A

Table 4-9 Decontamination factors for added manganese versus added hydroxide test matrix $\left(\mathrm{T}=50^{\circ} \mathrm{C}\right)$

\begin{tabular}{|c|c|ccccc|}
\multicolumn{1}{c}{} & \multicolumn{9}{c}{ DF Data } \\
Added $\mathrm{OH}^{-}(\mathrm{M})$ & Added $\mathrm{Mn}(\mathrm{M})$ & $\mathrm{Mn}$ & $\mathrm{Fe}$ & $\mathrm{La}$ & $\mathrm{Ce}$ & $\mathrm{Nd}$ \\
\hline 1 & 0.05 & 7.0 & 13.4 & 16.8 & 11.7 & 12.4 \\
0.5 & 0.05 & 8.9 & 16.0 & 15.3 & 12.1 & 12.3 \\
0.2 & 0.05 & 8.2 & 18.4 & 5.1 & $>16.6$ & 6.8 \\
0 & 0.05 & 1.0 & 3.6 & 2.3 & 2.1 & 1.9 \\
\hline 1 & 0.025 & 3.0 & 4.1 & 5.9 & 4.9 & 3.6 \\
0.5 & 0.025 & 3.3 & 3.9 & 5.2 & 4.8 & 3.6 \\
0.2 & 0.025 & 3.6 & 3.7 & 2.9 & 5.1 & 2.9 \\
0 & 0.025 & 1.0 & 1.9 & 1.3 & 1.6 & 1.3 \\
\hline 1 & 0.01 & 1.1 & 1.7 & 1.9 & 1.7 & 1.4 \\
0.5 & 0.01 & 1.3 & 1.8 & 2.1 & 1.8 & 1.6 \\
0.2 & 0.01 & 1.6 & 1.7 & 1.7 & 1.9 & 1.6 \\
0 & 0.01 & 1.1 & 1.9 & 1.3 & 1.6 & 1.3 \\
\hline
\end{tabular}

* corrected for sample dilution resulting from reagent addition

Table 4-10 Percent removals for added manganese versus added hydroxide test matrix $\left(\mathrm{T}=50^{\circ} \mathrm{C}\right)$

\begin{tabular}{|c|c|ccccc|}
\multicolumn{1}{c}{} & \multicolumn{7}{c|}{ \% Removal } \\
Added $\mathrm{OH}^{-}(\mathrm{M})$ & Added $\mathrm{Mn}(\mathrm{M})$ & $\mathrm{Mn}$ & $\mathrm{Fe}$ & $\mathrm{La}$ & $\mathrm{Ce}$ & $\mathrm{Nd}$ \\
\hline 1 & 0.05 & 86 & 93 & 94 & 91 & 92 \\
0.5 & 0.05 & 89 & 94 & 93 & 92 & 92 \\
0.2 & 0.05 & 88 & 95 & 80 & $>94$ & 85 \\
0 & 0.05 & 0 & 73 & 57 & 51 & 47 \\
\hline 1 & 0.025 & 67 & 75 & 83 & 79 & 72 \\
0.5 & 0.025 & 70 & 74 & 81 & 79 & 72 \\
0.2 & 0.025 & 72 & 73 & 66 & 80 & 66 \\
0 & 0.025 & 3 & 47 & 22 & 37 & 22 \\
\hline 1 & 0.01 & 12 & 40 & 47 & 41 & 30 \\
0.5 & 0.01 & 23 & 44 & 52 & 43 & 36 \\
0.2 & 0.01 & 36 & 42 & 42 & 47 & 36 \\
0 & 0.01 & 5 & 48 & 24 & 38 & 23 \\
\hline
\end{tabular}

* corrected for sample dilution resulting from reagent addition 
An additional manganese precipitation test was conducted under the baseline conditions in order to determine the time scale of lanthanide removal and evaluate whether decontamination corresponds to manganese solids formation. Sub-samples of the slurry were removed at approximately 1-minute intervals during the first 10 minutes immediately following permanganate reagent addition. An additional sample was collected after the 4hour reaction time. The slurry was not agitated with the impellor after the first 15 minutes. Samples were immediately filtered through $0.45 \mu \mathrm{m}$ nylon syringe filters directly into $6 \%$ nitric acid (dilution ratio 1:10). The acid dilution was intended to halt manganese precipitation immediately following filtration. ICP-ES analysis of rigorously digested and undigested samples indicated that no significant amounts of solids were present.

Plots of the $\mathrm{Mn}, \mathrm{Fe}$, and La decontamination factors versus sampling time are provided in Figures 4-9 and 4-10. The data shows a continual increase in DF throughout the 4-hour reaction period for all species except manganese. A manganese DF of 7 is obtained within 1.5 minutes after manganese reagent addition. Interestingly the manganese DF does not change throughout the reaction period. As discussed previously, the mechanism of manganese removal from AN-107 simulant is obviously different from the other species analyzed, as indicated by the atypical trends observed for manganese DF as a function of both temperature and time. Decontamination factors calculated for the lanthanides after 1.5 minutes averaged 3.8, which corresponds to $73 \%$ removal. After 10 minutes the average lanthanide decontamination is 7.4 ( $86 \%$ removal). After 4 hours the average lanthanide decontamination is 16.9 ( $94 \%$ removal). Not surprisingly, most of the lanthanide removal occurs within the first few minutes after permanganate reagent addition. However, the data indicates that additional lanthanide removal occurs with continued contact during the 4-hour reaction period, even though the slurry was not agitated during this period. Given that under these reaction conditions no measurable manganese solids form after the first 10 minutes, these observations indicate that approximately $10 \%$ lanthanide removal likely resulted from surface adsorption to manganese oxide solids.

\subsection{POST-FILTRATION PRECIPITATION ANALYSIS}

At the conclusion of each precipitation test, samples were filtered through $0.1 \mu \mathrm{m}$ nylon filters and analyzed by FBRM to confirm that no solids were present. The filtrates were then transferred to plastic filter cup bottoms, which were capped and stored in the dark. The air headspace above the solution was approximately four times the sample volume. Samples were measured periodically by FBRM over a 2.5 month period. FBRM data for the postfiltration samples is provided in the Appendix. Brown solids were often visually observed in both strontium and manganese precipitate filtrates within 1-2 days. No efforts were undertaken to physically scrape solids from the container walls prior to analysis. The samples were vigorously shaken to suspend as many solids as possible during analysis. This method was only marginally successful at removing solids adhering to the container walls. Therefore the total count data should be considered strictly qualitative as an indicator of whether or not significant solids formed. Chord length distributions for the post-filtration solids were often bimodal and appeared to contain two overlapping distributions that were often centered around 10 and $50 \mu \mathrm{m}$. 
WSRC-TR-2002-00364, REV. 0-A

SRT-RPP-2002-00194. REV. 0-A

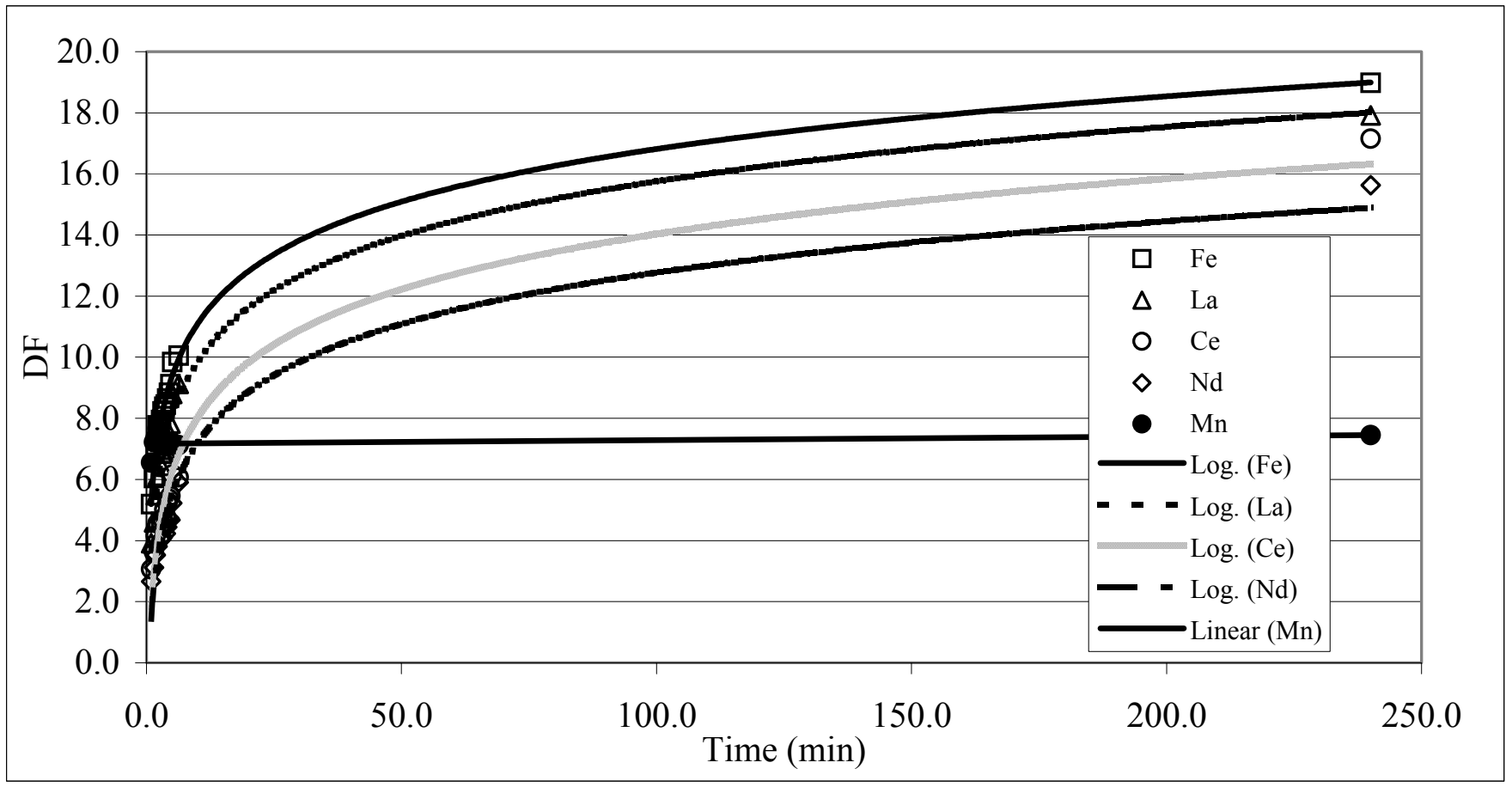

Figure 4-12 Manganese precipitation DF data versus time $\left(\mathrm{T}=50^{\circ} \mathrm{C}, 1.0 \mathrm{M}\right.$ added hydroxide, $0.05 \mathrm{M}$ added manganese)

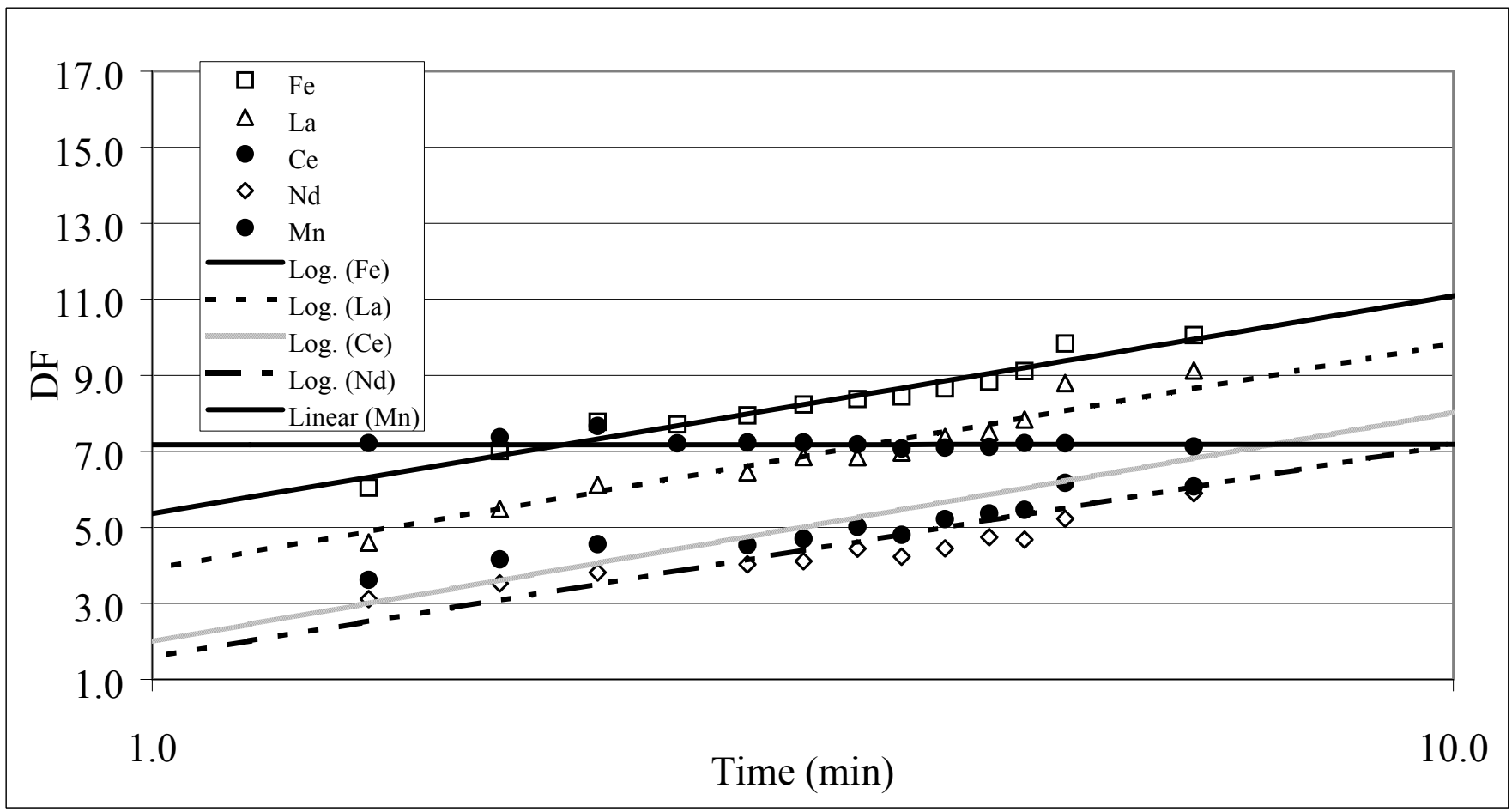

Figure 4-13 Manganese precipitation DF data versus time semi-log plot $\left(\mathrm{T}=50{ }^{\circ} \mathrm{C}, 1.0 \mathrm{M}\right.$ added hydroxide, $0.05 \mathrm{M}$ added manganese) 
Table 4-11 summarizes the general trends observed in the filtrate analysis. Conditions in bold type represent samples for which little or no post-filtration solids were observed. Filtered AN-107 simulant that was not caustic adjusted or exposed to strontium or manganese precipitation processes (Condition 7) formed no solids for several months. However, simulant adjusted to 1.0 M added hydroxide (Condition 6) forms significant amounts of solids within several days. With no added hydroxide, solids are not observed in the filtrate even after precipitation with $0.05 \mathrm{M}$ added manganese (Condition 8). With caustic-adjusted simulant, counts were often observed to increase with the added manganese reagent level (Figure 4-11). Significant solids were observed after nearly every test in which strontium was the only precipitating reagent (Condition 3). Interestingly, no solids were observed when the strontium precipitation was succeeded by $0.01 \mathrm{M}$ manganese reagent addition (condition 2). In summary, post-filtration solids formation appears to be strongly associated with simulant caustic adjustment. As was discussed in section 3.2, caustic adjustment alone leads to the formation of solids containing manganese and iron. Interestingly, 0.01 M manganese addition appears to prevent the formation of post-filtration solids.

Table 4-11 Summary of post-filtration precipitation data after $\geq \mathbf{3}$ days storage (samples with little or no solids indicated by bold type)

\begin{tabular}{|c|c|c|c|c|c|c|}
\hline Condition & $\begin{array}{l}\text { Added }[\mathrm{Sr}] \\
\text { (M) }\end{array}$ & $\begin{array}{l}\text { Added [Mn] } \\
\text { (M) }\end{array}$ & $\begin{array}{c}\text { Added }\left[\mathrm{OH}^{-}\right] \\
\text {(M) }\end{array}$ & counts/sec & $\begin{array}{l}\text { Mean Chord } \\
\text { micrometers }\end{array}$ & $\begin{array}{c}\text { Mean Squared } \\
\text { Chord }\end{array}$ \\
\hline 1 & 0.075 & 0.05 & 1.0 & $>2000$ & 10 & 300 \\
\hline 2 & 0.075 & 0.01 & 1.0 & $<100$ & 30 & 500 \\
\hline 3 & 0.075 & 0.0 & 1.0 & $>2000$ & 20 & 250 \\
\hline 4 & 0.0 & 0.05 & 1.0 & $>2000$ & 20 & 300 \\
\hline 5 & 0.0 & 0.01 & 1.0 & $<100$ & 30 & 450 \\
\hline 6 & 0.0 & 0.0 & 1.0 & $>1000$ & 20 & 250 \\
\hline 7 & 0.0 & 0.0 & 0.0 & $<\mathbf{1 0}$ & NA & NA \\
\hline 8 & 0.0 & 0.05 & 0.0 & $<100$ & 50 & 450 \\
\hline
\end{tabular}


WSRC-TR-2002-00364, REV. 0-A

SRT-RPP-2002-00194. REV. 0-A

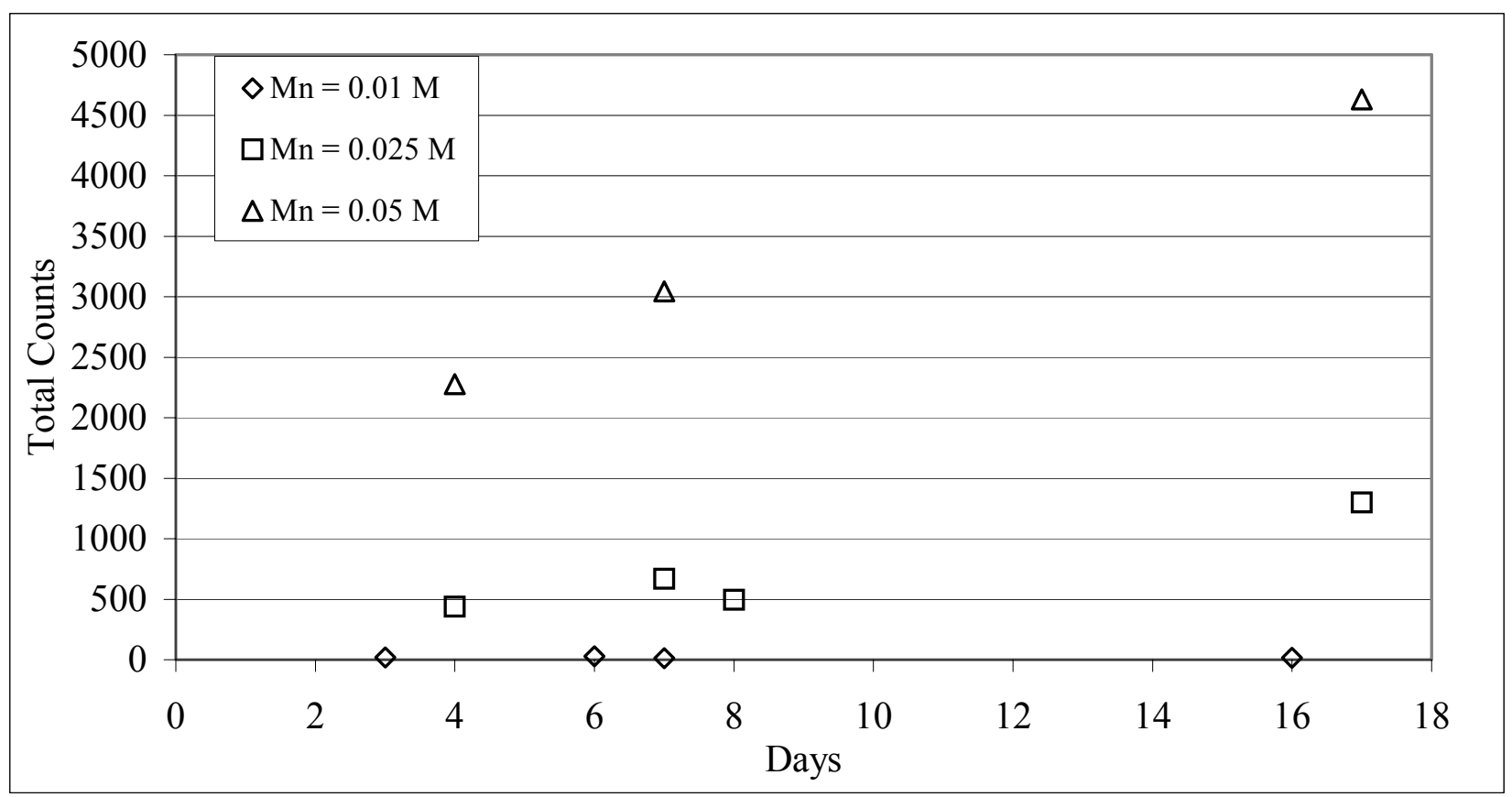

Figure 4-14 Total counts versus days for the formation of post-filtration precipitates (precipitation conditions: $\mathrm{T}=50^{\circ} \mathrm{C}, 0.5 \mathrm{M}$ added hydroxide)

\subsection{FUTURE WORK}

The authors recommend sensitivity studies on the impact of precipitate slurry storage temperature and filtration temperature upon filterability. Given the dramatic decrease in filterability reported herein which resulted from increasing the strontium slurry temperature prior to filtration, plant filtration may (at a minimum) need to be conducted at slightly lower temperatures than the precipitation reaction temperature.

Current work is scheduled at SRTC to evaluate the impacts of strontium/manganese precipitation upon ion exchange performance. The authors recommend FBRM analysis of AN-107 filtrate samples that are contacted with ion exchange resin, such that correlations can be developed between ion exchange resin performance and post-filtration solid distribution statistics. 


\subsection{REFERENCES}

1. Johnson, M. E. Sr/TRU Precipitation Reaction Rate Test Specification, TSP-W37501-00001, Rev. 0, (2001).

2. King, W. D. Task Technical and Quality Assurance Plan for Sr/TRU Reaction Rate Studies, WSRC-TR-2001-00261, Rev. 0, Savannah River Site, Aiken, SC 29808 (2001).

3. Eibling, R. E.; Nash, C. A. Hanford Waste Simulants Created to Support the Research and Development on the River Protection Project - Waste Treatment Plant. WSRC-TR-2000-00338, Rev. 0, Savannah River Site, Aiken, SC 29808 (2001).

4. Herting, D., WHC-SD-WM-DTR-040 (1995).

5. Nash, C. A.; Rosencrance, S. W.; Walker, B. W.; Wilmarth, B. R. Investigation of Varied Transuranic Precipitation Chemistries for Crossflow Filtration, BNF-003-980171, Rev. 0, Aiken, SC 29808 (2000).

6. Wilmarth, W. R.; Eibling, R. E.; Nash, C. A., Edwards, T. B. Phase I and Phase II Results from Sr and TRU Precipitation Tests, BNF-003-98-0180, Rev. 0, Aiken, SC 29808 (1999). 
WSRC-TR-2002-00364, REV. 0-A

SRT-RPP-2002-00194. REV. 0-A

\subsection{APPENDIX}

\subsection{STRONTIUM + MANGANESE POST FILTRATION PRECIPITATE CHORD LENGTH DISTRIBUTION DATA}

\begin{tabular}{|c|c|c|c|c|c|c|c|}
\hline $\begin{array}{c}\mathrm{T} \\
\left({ }^{\circ} \mathrm{C}\right) \\
\end{array}$ & $\begin{array}{c}\text { Added }\left[\mathrm{OH}^{-}\right] \\
(\mathrm{M})\end{array}$ & $\begin{array}{l}\text { Added }[\mathrm{Sr}] \\
(\mathrm{M})\end{array}$ & $\begin{array}{l}\text { Added [Mn] } \\
(\mathrm{M})\end{array}$ & Days & $\begin{array}{l}\text { Total } \\
\text { Counts }\end{array}$ & $\begin{array}{l}\text { Mean/Squared/ } \\
\text { Cubed Chord }\end{array}$ & Comments \\
\hline \multirow[t]{5}{*}{50} & 0.5 & 0.75 & 0.01 & 1 & 14 & $74 / 485 / 649$ & \\
\hline & & & & 4 & 24 & $48 / 481 / 658$ & \\
\hline & & & & 5 & 8 & $78 / 513 / 660$ & \\
\hline & & & & 14 & 40 & $29 / 565 / 733$ & new peak around 5- probable \\
\hline & & & & & & & $\begin{array}{l}\text { contaminant } \\
\text { counts excluding new peak-18 }\end{array}$ \\
\hline \multirow[t]{2}{*}{50} & 0.5 & 0.75 & 0.025 & 1 & 139 & $15 / 485 / 607$ & small amount fine solids \\
\hline & & & & 2 & 323 & $11 / 450 / 574$ & small amount fine solids \\
\hline \multirow[t]{4}{*}{50} & 0.5 & 0.75 & 0.05 & 1 & 562 & 10/488/701 & Broad peak \\
\hline & & & & 4 & 2920 & $10 / 256 / 609$ & \\
\hline & & & & 5 & 2632 & $12 / 270 / 668$ & \\
\hline & & & & 14 & 4263 & & \\
\hline \multirow[t]{4}{*}{50} & 0.2 & 0.75 & 0.025 & 1 & 28 & $43 / 501 / 658$ & bimodal-counts excluding left-12 \\
\hline & & & & 4 & 662 & $11 / 385 / 603$ & $\begin{array}{c}\text { still bimodal-broad peak with } \\
\text { hump on right }\end{array}$ \\
\hline & & & & 5 & 858 & 09/433/638 & \\
\hline & & & & 14 & 1475 & $8 / 431 / 663$ & \\
\hline \multirow[t]{2}{*}{50} & 1 & 0.75 & 0.01 & 1 & 38 & $31 / 492 / 615$ & fine brown film \\
\hline & & & & 2 & 81 & $21 / 475 / 611$ & few fine brown solids \\
\hline \multirow[t]{2}{*}{50} & 1 & 0.75 & 0.025 & 1 & 1022 & $10 / 407 / 617$ & small amount fine solids \\
\hline & & & & 2 & 1544 & $10 / 362 / 629$ & small amount fine solids \\
\hline 50 & 1 & 0.75 & 0.05 & 1 & 1534 & $11 / 382 / 620$ & small amount fine solids \\
\hline
\end{tabular}


WSRC-TR-2002-00364, REV. 0-A

SRT-RPP-2002-00194. REV. 0-A

\subsection{STRONTIUM POST FILTRATION PRECIPITATE CHORD LENGTH DISTRIBUTION DATA}

\begin{tabular}{|c|c|c|c|c|c|c|c|}
\hline $\begin{array}{c}\mathrm{T} \\
\left({ }^{\circ} \mathrm{C}\right)\end{array}$ & $\begin{array}{l}\text { Added }\left[\mathrm{OH}^{-}\right] \\
(\mathrm{M})\end{array}$ & $\begin{array}{l}\text { Added [Sr] } \\
\text { (M) }\end{array}$ & $\begin{array}{l}\text { Added [Mn] } \\
\text { (M) }\end{array}$ & Days & $\begin{array}{l}\text { Total } \\
\text { Counts }\end{array}$ & $\begin{array}{l}\text { Mean/Squared/ } \\
\text { Cubed Chord }\end{array}$ & Comments \\
\hline \multirow[t]{2}{*}{50} & 0.2 & 0.02 & 0 & 2 & 1338 & $17 / 192 / 400$ & Significant fine solids \\
\hline & & & & 3 & 1664 & $17 / 174 / 404$ & significant fine solids \\
\hline \multirow[t]{2}{*}{50} & 0.2 & 0.05 & 0 & 2 & 1126 & $16 / 226 / 489$ & significant fine solids \\
\hline & & & & 3 & 1462 & $16 / 185 / 462$ & significant fine solids \\
\hline \multirow[t]{2}{*}{50} & 0.2 & 0.075 & 0 & 2 & 1301 & $12 / 279 / 533$ & significant fine solids \\
\hline & & & & 3 & 1776 & $13 / 172 / 441$ & significant fine solids \\
\hline \multirow[t]{2}{*}{50} & 1 & 0.02 & 0 & 1 & 1247 & $14 / 275 / 569$ & significant fine solids \\
\hline & & & & 2 & 2074 & $12 / 214 / 535$ & significant fine solids \\
\hline \multirow[t]{2}{*}{50} & 1 & 0.05 & 0 & 2 & 2334 & $16 / 177 / 489$ & significant fine solids \\
\hline & & & & 3 & 1929 & $16 / 145 / 449$ & significant fine solids \\
\hline \multirow[t]{2}{*}{50} & 1 & 0.075 & 0 & 2 & 1247 & $17 / 251 / 586$ & significant fine solids, bimodal \\
\hline & & & & 3 & 1929 & $16 / 145 / 449$ & significant fine solids, bimodal \\
\hline \multirow[t]{2}{*}{25} & 1 & 0.02 & 0 & $<1$ & 571 & $11 / 424 / 627$ & cloudy solution \\
\hline & & & & 2 & 907 & $11 / 349 / 573$ & film of brown solids \\
\hline \multirow[t]{2}{*}{25} & 1 & 0.05 & 0 & $<1$ & 303 & $13 / 473 / 643$ & thin film of solids \\
\hline & & & & 2 & 552 & $12 / 420 / 649$ & film of brown solids, cloudy \\
\hline \multirow[t]{2}{*}{25} & 1 & 0.075 & 0 & $<1$ & 422 & $16 / 351 / 590$ & thin film of solids \\
\hline & & & & 2 & 654 & $14 / 347 / 647$ & $\begin{array}{c}\text { film of brown solids, cloudy } \\
\text { solution }\end{array}$ \\
\hline \multirow[t]{2}{*}{25} & 1 & 0.02 & 0 & $<1$ & 672 & $13 / 362 / 584$ & film of brown solids \\
\hline & & & & 2 & 692 & $13 / 368 / 613$ & film of brown solids \\
\hline \multirow[t]{2}{*}{25} & 1 & 0.05 & 0 & $<1$ & 213 & $14 / 385 / 541$ & no visible solids \\
\hline & & & & 2 & 266 & $13 / 372 / 524$ & $\begin{array}{c}\text { film of brown solids, cloudy } \\
\text { solution }\end{array}$ \\
\hline \multirow[t]{2}{*}{25} & 1 & 0.075 & 0 & $<1$ & 582 & $15 / 358 / 600$ & thin film of solids \\
\hline & & & & 2 & 248 & $16 / 401 / 590$ & $\begin{array}{c}\text { film of brown solids, cloudy } \\
\text { solution }\end{array}$ \\
\hline
\end{tabular}


WSRC-TR-2002-00364, REV. 0-A

SRT-RPP-2002-00194. REV. 0-A

\subsection{MANGANESE POST FILTRATION PRECIPITATE CHORD LENGTH DISTRIBUTION DATA}

\begin{tabular}{|c|c|c|c|c|c|c|c|}
\hline $\begin{array}{c}\mathrm{T} \\
\left({ }^{\circ} \mathrm{C}\right)\end{array}$ & $\begin{array}{l}\text { Added }\left[\mathrm{OH}^{-}\right] \\
(\mathrm{M})\end{array}$ & $\begin{array}{l}\text { Added }[\mathrm{Sr}] \\
\quad(\mathrm{M})\end{array}$ & $\begin{array}{l}\text { Added [Mn] } \\
(\mathrm{M})\end{array}$ & Days & $\begin{array}{l}\text { Total } \\
\text { Counts }\end{array}$ & $\begin{array}{l}\text { Mean/Squared/ } \\
\text { Cubed Chord }\end{array}$ & Comments \\
\hline \multirow[t]{2}{*}{15} & 1 & 0 & 0.01 & 6 & 17 & $63 / 509 / 693$ & \\
\hline & & & & 61 & 155 & $11 / 500 / 667$ & no solids observed \\
\hline \multirow[t]{2}{*}{15} & 1 & 0 & 0.025 & 6 & 162 & $28 / 388 / 627$ & bimodal 8/50 larger on coarse \\
\hline & & & & 61 & 3580 & & thin brown layer of solids \\
\hline \multirow[t]{2}{*}{15} & 1 & 0 & 0.05 & 6 & 899 & 39/209/395 & \\
\hline & & & & 61 & 1529 & & $\begin{array}{c}\text { bimodal } 5 / 50 \\
\text { significant amount of solids }\end{array}$ \\
\hline \multirow[t]{3}{*}{25} & 1 & 0 & 0.01 & 3 & 35 & $65 / 401 / 571$ & $\begin{array}{l}\text { noisy peak around } 50 \text { with } \\
\text { small hump on } \\
\text { coarse side }\end{array}$ \\
\hline & & & & 4 & 23 & $56 / 513 / 661$ & \\
\hline & & & & 13 & 95 & $24 / 469 / 635$ & $\begin{array}{l}\text { single sharp peak probably } \\
\text { contaminant } \\
\text { counts excluding sharp peak } \\
16\end{array}$ \\
\hline \multirow[t]{3}{*}{25} & 1 & 0 & 0.025 & 4.00 & 468 & $27 / 218 / 512$ & Bimodal $6 \& 32$ \\
\hline & & & & 13 & 2028 & $14 / 225 / 602$ & $\begin{array}{c}\text { Left peak half of right } \\
\text { Left peak has grown to } 3-4 \\
\text { times right }\end{array}$ \\
\hline & & & & 68 & 3574 & $18 / 266 / 379$ & $\begin{array}{l}\text { only small peak on right } \\
\text { thick layer of solids }\end{array}$ \\
\hline \multirow[t]{3}{*}{25} & 1 & 0 & 0.05 & 1 & 18 & $55 / 533 / 677$ & bimodal $8 / 50$ \\
\hline & & & & 10 & 1470 & $33 / 308 / 395$ & $\begin{array}{c}\text { bimodal } 10 / 150 \text { large peak on } \\
\text { left }\end{array}$ \\
\hline & & & & 65 & 2551 & $27 / 309 / 396$ & sig. Solids \\
\hline 50 & 1 & 0 & 0.01 & $\begin{array}{c}9 \\
64\end{array}$ & 99 & $29 / 425 / 628$ & sharp peak \\
\hline 50 & 1 & 0 & 0.025 & $\begin{array}{l}9 \\
64\end{array}$ & 4011 & $11 / 223 / 615$ & \\
\hline 50 & 1 & 0 & 0.05 & $\begin{array}{c}9 \\
64\end{array}$ & 3169 & $22 / 289 / 427$ & \\
\hline \multirow[t]{4}{*}{50} & 0.5 & 0 & 0.01 & 3 & 18 & $128 / 369 / 523$ & bimodal 8/50 \\
\hline & & & & 6 & 29 & $71 / 436 / 627$ & left peak growing \\
\hline & & & & 7 & 13 & $90 / 505 / 657$ & monomodal, noisy \\
\hline & & & & 16 & 16 & $70 / 482 / 619$ & \\
\hline \multirow[t]{4}{*}{50} & 0.5 & 0 & 0.025 & 4 & 438 & $13 / 411 / 627$ & \\
\hline & & & & 7 & 670 & $10 / 403 / 643$ & \\
\hline & & & & 8 & 495 & $10 / 472 / 648$ & \\
\hline & & & & 17 & 1301 & 9/373/612 & \\
\hline \multirow[t]{3}{*}{50} & 0.5 & 0 & 0.05 & 4 & 2278 & $10 / 332 / 666$ & \\
\hline & & & & 7 & 3043 & $11 / 218 / 576$ & \\
\hline & & & & 17 & 4631 & $20 / 176 / 316$ & \\
\hline
\end{tabular}


WSRC-TR-2002-00364, REV. 0-A

SRT-RPP-2002-00194. REV. 0-A

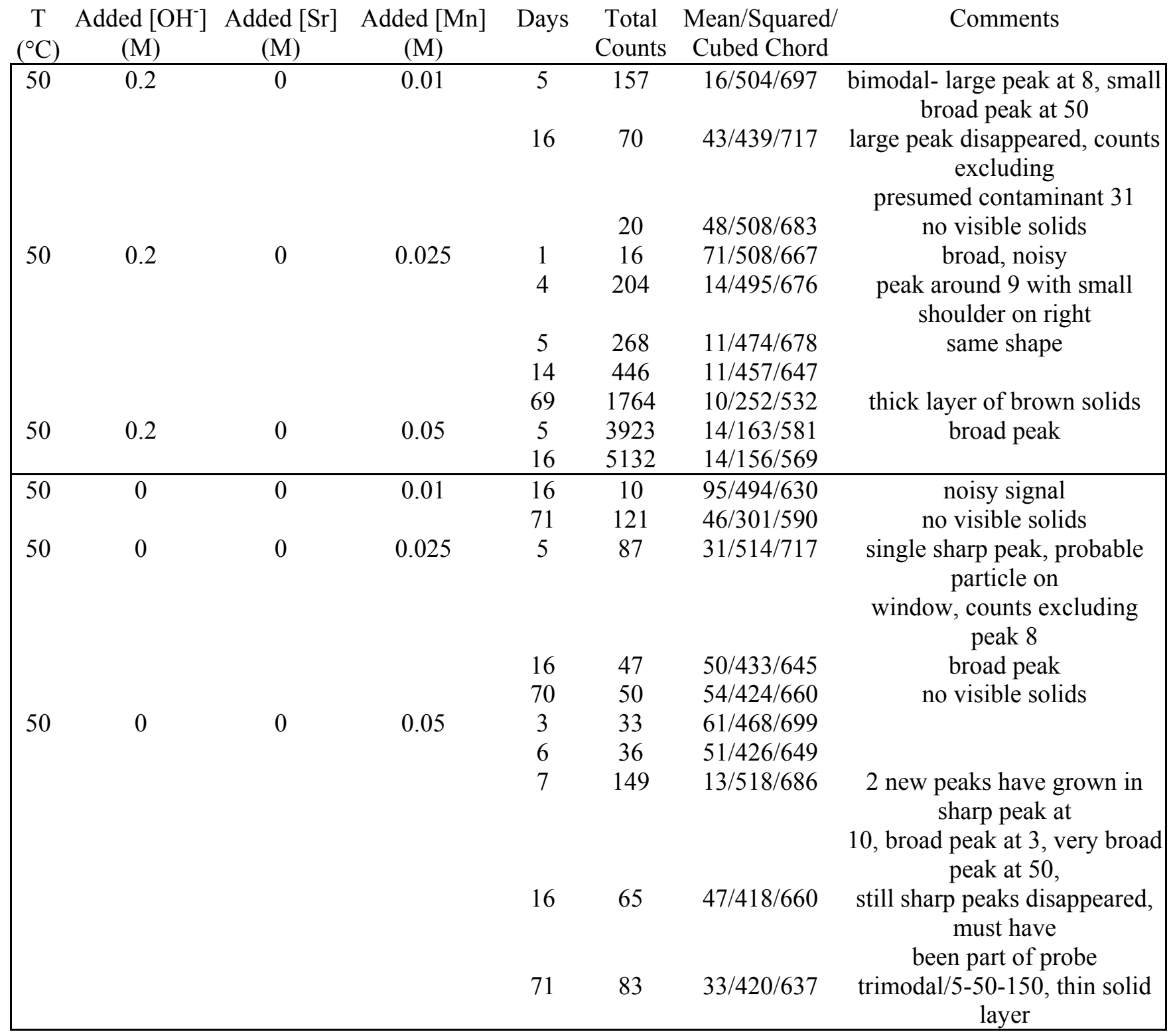

